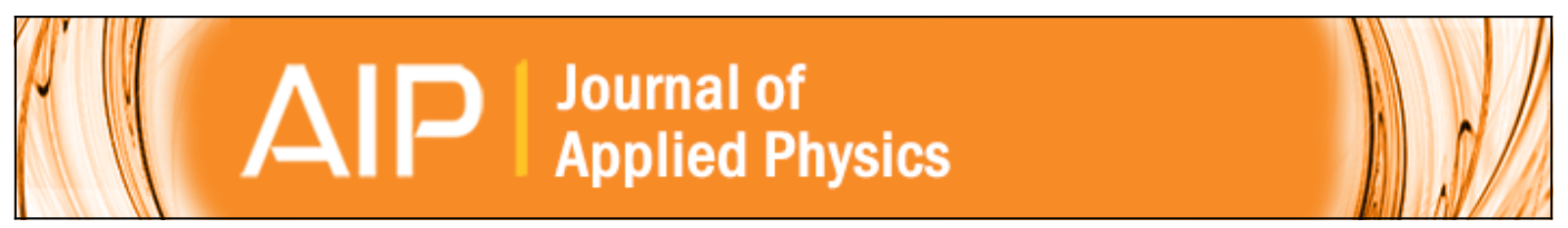

\title{
Oxygen transport in the internal xenon plasma of a dispenser hollow cathode
}

Angela M. Capece, James E. Polk, loannis G. Mikellides, and Joseph E. Shepherd

Citation: Journal of Applied Physics 115, 153302 (2014); doi: 10.1063/1.4871755

View online: http://dx.doi.org/10.1063/1.4871755

View Table of Contents: http://scitation.aip.org/content/aip/journal/jap/115/15?ver=pdfcov

Published by the AIP Publishing

\section{Articles you may be interested in}

The effect of cathode geometry on barium transport in hollow cathode plasmas

J. Appl. Phys. 115, 183301 (2014); 10.1063/1.4873168

Effect of Ti-Al cathode composition on plasma generation and plasma transport in direct current vacuum arc J. Appl. Phys. 115, 123301 (2014); 10.1063/1.4869199

Laser induced fluorescence of the ferroelectric plasma source assisted hollow anode discharge

Phys. Plasmas 16, 113504 (2009); 10.1063/1.3263696

Tungsten and barium transport in the internal plasma of hollow cathodes

J. Appl. Phys. 105, 113301 (2009); 10.1063/1.3111970

Tailoring of ion species composition in complex plasmas with charge exchange collisions

Phys. Plasmas 12, 062105 (2005); 10.1063/1.1925547

\section{AlP Re-register for Table of Content Alerts}




\title{
Oxygen transport in the internal xenon plasma of a dispenser hollow cathode
}

\author{
Angela M. Capece, ${ }^{1, a)}$ James E. Polk, ${ }^{2}$ Ioannis G. Mikellides, ${ }^{2}$ and Joseph E. Shepherd ${ }^{1}$ \\ ${ }^{1}$ California Institute of Technology, Pasadena, California 91125, USA \\ ${ }^{2}$ Jet Propulsion Laboratory, 4800 Oak Grove Dr., Pasadena, California 91109, USA
}

(Received 13 February 2014; accepted 6 April 2014; published online 18 April 2014)

\begin{abstract}
Reactive gases such as oxygen and water vapor modify the surface morphology of $\mathrm{BaO}$ dispenser cathodes and degrade the electron emission properties. For vacuum cathodes operating at fixed temperature, the emission current drops rapidly when oxygen adsorbs on top of the low work function surface. Previous experiments have shown that plasma cathodes are more resistant to oxygen poisoning and can operate with $\mathrm{O}_{2}$ partial pressures one to two orders of magnitude higher than vacuum cathodes before the onset of poisoning occurs. Plasma cathodes used for electric thrusters are typically operated with xenon; however, gas phase barium, oxygen, and tungsten species may be found in small concentrations. The densities of these minor species are small compared with the plasma density, and thus, their presence in the discharge does not significantly alter the xenon plasma parameters. It is important, however, to consider the transport of these minor species as they may deposit on the emitter surface and affect the electron emission properties. In this work, we present the results of a material transport model used to predict oxygen fluxes to the cathode surface by solving the species conservation equations in a cathode with a $2.25 \mathrm{~mm}$ diameter orifice operated at a discharge current of $15 \mathrm{~A}$, a Xe flow rate of $3.7 \mathrm{sccm}$, and $100 \mathrm{ppm}$ of $\mathrm{O}_{2}$. The dominant ionization process for $\mathrm{O}_{2}$ is resonant charge exchange with xenon ions. $\mathrm{Ba}$ is effectively recycled in the plasma; however, $\mathrm{BaO}$ and $\mathrm{O}_{2}$ are not. The model shows that the oxygen flux to the surface is not diffusion-limited; therefore, the high resistance to oxygen poisoning observed in plasma cathodes likely results from surface processes not considered here. (C) 2014 AIP Publishing LLC. [http://dx.doi.org/10.1063/1.4871755]
\end{abstract}

\section{INTRODUCTION}

Hollow cathodes are one of the main life-limiting components in electric thrusters, which are often required to operate in excess of $10000 \mathrm{~h}$. State-of-the-art hollow cathodes consist of a porous tungsten tube that is heated using an external resistive heater until it reaches the temperature for thermionic emission. Neutral xenon gas is injected into the cathode and is ionized via electron impact creating a plasma. An orifice plate is located downstream of the tungsten emitter to increase the gas pressure inside the hollow cathode.

A low emitter operating temperature is essential for extending cathode lifetime. This is achieved for cathodes operating at fixed current density by maintaining a low work function surface. When barium atoms are adsorbed on an oxygen monolayer on top of the tungsten substrate, $\mathrm{a} \mathrm{Ba}^{+} \mathrm{O}^{-}$ dipole forms that reduces the work function from $4.5 \mathrm{eV}$ for tungsten to less than $2.1 \mathrm{eV}{ }^{1} \mathrm{Ba}$ and $\mathrm{BaO}$ are generated by impregnating the cathode with a $\mathrm{BaO}-\mathrm{CaO}-\mathrm{Al}_{2} \mathrm{O}_{3}$ source material that reacts with the tungsten matrix to release $\mathrm{Ba}$ and $\mathrm{BaO}$ that then migrate to the surface via Knudsen flow and surface diffusion on the pore walls.

Contaminants such as oxygen and water vapor, which may be introduced into the xenon flow via leaks, propellant

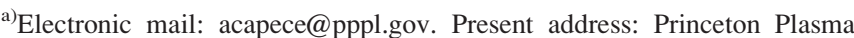
Physics Laboratory, Princeton, New Jersey 08543, USA. This research was performed while A. M. Capece was at the California Institute of Technology, Pasadena, California 91125, USA.
}

impurities, and residual chemicals in the feed system, can interact with the cathode material, altering the emitter surface structure and cathode chemistry. Excess oxygen adsorbs onto the emitter surface and disturbs the $\mathrm{Ba}^{+} \mathrm{O}^{-}$dipole, resulting in degradation of the electron emission properties. Haas et al. showed that the work function of a $\mathrm{BaO}$ cathode increased to $2.9 \mathrm{eV}$ following exposure to $10 \mathrm{~L}$ of $\mathrm{O}_{2}{ }^{2}$ An increase in the surface work function will increase the operating temperature for cathodes operating at fixed current density. This accelerates the evaporation of the barium oxide source material, resulting in reduced cathode life.

Cronin showed that the emission current of a vacuum cathode operating at $1000{ }^{\circ} \mathrm{C}$ dropped off rapidly at oxygen partial pressures above $10^{-7}$ Torr. $^{3}$ However, oxygen poisoning in discharge cathodes begins to occur at oxygen partial pressures between $10^{-6}$ and $10^{-5}$ Torr, indicating that plasma cathodes are more resistant to oxygen poisoning than vacuum dispenser cathodes. ${ }^{4}$ A significant amount of work has been done previously to understand the effects of oxygen poisoning in vacuum cathodes; ${ }^{2,3,5-12}$ however, the xenon plasma adds complexity, and its role during cathode poisoning in discharge cathodes is not completely understood. In this work, we present the results of a material transport model used to predict the oxygen fluxes to the cathode surface that can later be used in kinetics models to understand the dynamics of oxygen poisoning at the plasma-surface interface.

The Xe discharge plasma is primarily composed of Xe neutrals, $\mathrm{Xe}^{+}$ions, and electrons. However, gas phase barium, 
oxygen, and tungsten species are also found in small concentrations. The densities of these minor species are small compared with the plasma and Xe neutral densities, and thus, their presence in the discharge does not significantly alter the Xe plasma parameters. Transport of these particles is governed by the conservation equations and interactions with the Xe plasma. Key physical interaction processes include collisions with electrons, $\mathrm{Xe}^{+}$ions, and Xe neutrals resulting in momentum transfer, charge exchange, recombination, and ionization. Ionized minor species are also accelerated due to the potential gradients in the plasma. In order to compute the distribution of minor species, the physical interactions and transport processes have been implemented in a numerical simulation of the hollow cathode geometry.

The hollow cathode transport model was first developed and presented by Polk et al. to describe the diffusion of Ba through the Xe discharge. ${ }^{13-15}$ Polk et al. have shown that $\mathrm{Ba}$ is supplied to the emitter surface through the gas phase and is recycled within the cathode. Ba evaporates from the insert, is ionized in the plasma, and is transported back to the surface via the electric field and $\mathrm{Xe}^{+}$ion drag. ${ }^{15}$ The $\mathrm{Ba}$ deposited on the emitter provides enough coverage to sustain the low work function surface even in regions where the pores may be blocked and Ba supply from the interior is inhibited. This conclusion is significant as it shows that Ba depletion is not as crucial to the lifetime of plasma cathodes as it is to vacuum cathodes.

The work presented here expands upon the transport model of Polk et al. ${ }^{15}$ to include $\mathrm{BaO}$ and to model the dynamics during $100 \mathrm{ppm}$ of oxygen poisoning for a cathode with a $2.25 \mathrm{~mm}$ diameter orifice operated at a discharge current of $15 \mathrm{~A}$ and a Xe flow rate of $3.7 \mathrm{sccm}$. The minor species considered in this work include: $\mathrm{Ba}, \mathrm{Ba}^{+}, \mathrm{BaO}$, $\mathrm{BaO}^{+}, \mathrm{O}_{2}, \mathrm{O}_{2}{ }^{+}, \mathrm{O}$, and $\mathrm{O}^{+}$. The continuity and momentum equations governing the minor species transport are solved using inputs from a Xe plasma model developed separately by Mikellides et al. ${ }^{16-18}$ The results of the Xe plasma model show that the cathode generates a high density, low temperature plasma. The neutral and plasma densities are on the order of $10^{21}$ and $10^{20} \mathrm{~m}^{-3}$, respectively. The heavy particle temperature is between 1300 and $1750 \mathrm{~K}$, and typical electron temperatures are between 1.6 and $2.2 \mathrm{eV}$. The addition of minor species is assumed to not significantly affect the results of the Xe plasma solution, and therefore, the Xe plasma and minor species transport models may be solved sequentially. $\mathrm{Ba}$ and $\mathrm{BaO}$ are introduced into the gas via evaporation from the emitter pores, and ions are generated via electron impact ionization. The addition of $\mathrm{BaO}$ in the model does not change the $\mathrm{Ba}$ solution presented previously by Polk et al. ${ }^{13-15}$ Once the $\mathrm{Ba} / \mathrm{BaO}$ solution reaches equilibrium, $\mathrm{O}_{2}$ is introduced into the discharge to simulate oxygen poisoning. The transport of tungsten oxide species in the discharge is not modeled as the densities of these species are expected to be small compared with barium and oxygen.

\section{MINOR SPECIES TRANSPORT EQUATIONS}

The transport of minor species through the xenon plasma is described using the following form of the conservation equations. The continuity equation for species $j$ in a gas mixture is

$$
\frac{\partial}{\partial t}\left(n_{j} m_{j}\right)+\nabla \cdot\left(n_{j} m_{j} \mathbf{u}_{j}\right)=m_{j} \dot{n}_{j, \text { gen }},
$$

where $n_{j}$ is the density, $m_{j}$ is the mass, $\mathbf{u}_{j}$ is the mean species velocity, and $\dot{n}_{j, \text { gen }}$ is the generation rate of species $j$. The species momentum transfer equation for a nonreactive gas containing a mixture of two species is ${ }^{19}$

$$
\frac{\partial}{\partial t}\left(n_{j} m_{j} \mathbf{u}_{j}\right)+\nabla \cdot\left(n_{j} m_{j} \mathbf{u}_{j} \mathbf{u}_{j}\right)=-\nabla P_{j}+n_{j} m_{j} \mathbf{F}_{j}+\boldsymbol{\beta}_{j k},
$$

where classical viscous momentum transfer is neglected, $P_{j}=n_{j} k T$ is the partial pressure of species $j, \mathbf{F}_{j}$ accounts for an external applied force, and $\boldsymbol{\beta}_{j k}$ is the momentum transferred to species $j$ during collisions with species $k$ and is approximated by

$$
\boldsymbol{\beta}_{j k}=n_{j} \nu_{j k} \mu_{j k}\left(\mathbf{u}_{k}-\mathbf{u}_{j}\right) .
$$

The collision frequency between $j$ and $k$ particles is given by $\nu_{j k}$, and $\mu_{j k}$ is the reduced mass. For a reactive mixture, the following source term must be added to the right-hand side of Eq. (2) to account for the change in the total momentum by the creation or annihilation of species $j$ particles:

$$
m_{j}\left(S_{j} \mathbf{u}_{j, \text { birth }}-R_{j} \mathbf{u}_{j, \text { death }}\right),
$$

where $S_{j}$ is the rate at which $j$ particles are created, $\mathbf{u}_{j, \text { birth }}$ is the average velocity of newly created $j$ particles, $R_{j}$ is the rate at which $j$ particles are lost, and $\mathbf{u}_{j \text {,death }}$ is the mean velocity when they are lost. The difference between $S_{j}$ and $R_{j}$ is equivalent to the generation rate of species $j$, i.e., $\dot{n}_{j, \text { gen }}=S_{j}-R_{j}$. We assume that $\mathbf{u}_{j, \text { birth }}=\mathbf{u}_{j, \text { death }}=\mathbf{u}_{j}$, such that $S_{j} \mathbf{u}_{j, \text { birth }}-R_{j} \mathbf{u}_{j, \text { death }}=\dot{n}_{j, \text { gen }} \mathbf{u}_{j}$.

The terms on the left hand side of Eq. (2) are expanded and combined with Eq. (1) to yield

$$
\begin{aligned}
n_{j} m_{j} \frac{\partial}{\partial t} \mathbf{u}_{j}+n_{j} m_{j}\left(\mathbf{u}_{j} \cdot \nabla\right) \mathbf{u}_{j}= & -\nabla P_{j}+n_{j} q_{j}\left(\mathbf{E}+\mathbf{u}_{j} \times \mathbf{B}\right) \\
& +n_{j} \nu_{j k} \mu_{j k}\left(\mathbf{u}_{k}-\mathbf{u}_{j}\right),
\end{aligned}
$$

where $\mathbf{F}_{j}$ is replaced by the Lorentz force, which acts on the ions, and where $q_{j}$ is the particle charge, $\mathbf{E}$ is the electric field, and $\mathbf{B}$ is the magnetic field. If we neglect the magnetic field effects and the acceleration terms on the left hand side of Eq. (5) under the assumption that the bulk motion of species $j$ is slow, the momentum equation simplifies to

$$
0=-\nabla P_{j}+n_{j} q_{j} \mathbf{E}+n_{j} \nu_{j k} \mu_{j k}\left(\mathbf{u}_{k}-\mathbf{u}_{j}\right) .
$$

For neutral particles, there are no externally applied forces and Eq. (6) can be written in the form of a diffusion equation

$$
\mathbf{u}_{j}-\mathbf{u}_{k}=-\frac{k T}{\nu_{j k} \mu_{j k}} \frac{1}{P_{j}} \nabla P_{j}
$$


where $\left(\mathbf{u}_{j}-\mathbf{u}_{k}\right)$ is the differential motion due to diffusion and $D_{j k}=k T / \nu_{j k} \mu_{j k}$ can be identified as the conventional binary diffusion coefficient. ${ }^{19}$ In this formulation of momentum transport, $\boldsymbol{\beta}_{j k}$ is a molecular-level representation of diffusive species transport.

This model is extended to a system with eight minor species: $\mathrm{Ba}, \mathrm{Ba}^{+}, \mathrm{O}, \mathrm{O}^{+}, \mathrm{O}_{2}, \mathrm{O}_{2}^{+}, \mathrm{BaO}$, and $\mathrm{BaO}^{+}$diffusing through a gas mixture containing three major species: $e^{-}$, $\mathrm{Xe}$, and $\mathrm{Xe}^{+}$. Since the density of each minor species in the gas is several orders of magnitude lower than the major species densities, we assume that the minor species only experience momentum exchange with the major species and drag between minor species is neglected.

The collision term in Eq. (6) is modified to account for collisions with each of the three major species

$$
\boldsymbol{\beta}_{j k}=\sum_{k} n_{j} \nu_{j k} \mu_{j k}\left(\mathbf{u}_{k}-\mathbf{u}_{j}\right)
$$

where the subscript $j$ refers to each of the minor species and the subscript $k$ refers to each of the major species.

We expand the final term on the right-hand side of Eq. (6) and solve for the flux, $\boldsymbol{\Gamma}_{j}=n_{j} \mathbf{u}_{j}$, to obtain

$$
\boldsymbol{\Gamma}_{j}=n_{j} \mathbf{u}_{j}=\frac{1}{\sum_{k} \nu_{j k} \mu_{j k}}\left(-\nabla P_{j}+n_{j} q_{j} \mathbf{E}+n_{j} \sum_{k} \nu_{j k} \mu_{j k} \mathbf{u}_{k}\right) .
$$

Equations (1) and (9) represent a set of 16 equations, where the unknown quantities are the velocity, $\mathbf{u}_{j}$, and number density, $n_{j}$, of each minor species. All other quantities are precalculated in the Xe plasma simulation and are assumed to be independent of the dynamics of the barium and oxygen plasma. The equations are discretized using a finite volume approach and are solved on a two-dimensional axisymmetric mesh $2 \mathrm{~cm}$ long with a radius $0.189 \mathrm{~cm}$.

All vector quantities are edge-centered; all scalar quantities are cell-centered. The minor species fluxes were calculated via Eq. (9). The initial densities of $\mathrm{Ba}$ and $\mathrm{BaO}$ were assumed to be uniform throughout the cathode. The flux values were substituted into Eq. (1), which was then evolved in time until the densities and fluxes achieved steady-state values. Since oxygen was introduced at the cathode inlet, the densities of $\mathrm{O}, \mathrm{O}^{+}, \mathrm{O}_{2}$, and $\mathrm{O}_{2}^{+}$were initially assumed to be zero everywhere. Using the divergence theorem, the discretized form of the continuity equation given in Eq. (1) is

$$
n_{\text {new }}=n_{\text {old }}+d t\left(\dot{n}_{\text {gen }}-\frac{1}{V} \sum_{\alpha=1}^{4} \boldsymbol{\Gamma}_{\alpha} \cdot \mathbf{A}_{\alpha}\right)
$$

where $V$ is the cell volume, $d t$ is the time step and is on the order of $1 \mathrm{~ns}, \boldsymbol{\Gamma}_{\alpha}$ represents the flux across edge $\alpha$, and $\mathbf{A}_{\alpha}$ is the area of edge $\alpha$.

\section{GAS PHASE REACTIONS IN THE XENON PLASMA}

The gas phase reactions considered in this work include momentum transfer, electron impact ionization, charge exchange, and chemical reactions. Three-body electron attachment to $\mathrm{O}_{2}$ molecules was not included here as the rate constant for this reaction is on the order of $10^{-44} \mathrm{~m}^{6} / \mathrm{s}$ assuming $\mathrm{Xe}$ is the third body, ${ }^{20}$ and the frequency for this reaction is $10^{-4} \mathrm{~s}^{-1}$, which is many orders of magnitude lower than the other reactions considered here.

Electron-neutral collisions. The collision frequencies for momentum transfer during electron-neutral collisions were obtained by integrating momentum transfer cross sections for collisions between electrons and $\mathrm{O}, \mathrm{O}_{2}$, and $\mathrm{Ba}$ over a Maxwellian velocity distribution. ${ }^{21-23}$

Electron impact ionization also results from these collisions. The ion generation rate of species $j$ is the product of the neutral density of species $j$ and the ionization rate

$$
\dot{n}_{j^{i}, \text { gen }}=n_{j} \nu_{j^{n}, e}^{i z}
$$

The ionization rate was obtained by integrating electron impact ionization cross sections for $\mathrm{O}, \mathrm{O}_{2}, \mathrm{Ba}$, and $\mathrm{BaO}$ over a Maxwellian velocity distribution. ${ }^{24-28}$ For the ionization of $\mathrm{BaO}$, Hastie et al. measured a single maximum cross section of $\sigma_{m}=1.7 \times 10^{-16} \mathrm{~cm}^{2}$ at an electron energy of $E_{m}=26$ $\mathrm{eV}^{27}$ This value of $\sigma_{m}$ is scaled over a range of energy values using the following analytical model: ${ }^{28}$

$$
\sigma(E)=\frac{3.86 \sigma_{m}\left(\frac{E-\Phi}{E_{m}-\Phi}\right)^{1.127}}{\left(0.8873+\frac{E-\Phi}{E_{m}-\Phi}\right)^{2.127}}
$$

where $\Phi=6.91 \mathrm{eV}$ is the ionization potential of $\mathrm{BaO}$.

Electron-ion collisions. The electron-ion Coulomb collision frequency is given by ${ }^{29}$

$$
\nu_{j^{i}, e}=n_{e} \frac{\sqrt{2}}{3 \sqrt{\pi}}\left(\frac{e^{2}}{4 \pi \epsilon_{0}}\right)^{2} \frac{4 \pi}{\left(e T_{e}\right)^{3 / 2}} \frac{\mu_{j^{i}, e}^{1 / 2}}{m_{j^{i}}} \ln \Lambda
$$

where the Coulomb logarithm for electron-ion collisions is ${ }^{29}$

$$
\ln \Lambda_{e i}=23-\ln \left(1 \times 10^{-3} n_{e}^{1 / 2} Z T_{e}^{-3 / 2}\right),
$$

and is valid for $T_{i} m_{e} / m_{i}<T_{e}<10 Z^{2} \mathrm{eV} . T_{e}$ and $T_{i}$ are the electron and ion temperatures, respectively, and are given in units of eV. $n_{e}$ is the electron density in $\mathrm{m}^{-3}, e \mathrm{Z}$ is the particle charge, and $m_{e}$ and $m_{i}$ are the electron and ion masses, respectively.

Electron-ion recombination of the minor species is not considered in the plasma since the electron-ion collision frequencies are several orders of magnitude lower than the electron-neutral collision frequencies.

Mixed ion-ion collisions. The Coulomb collision frequency for collisions between minor species ions and $\mathrm{Xe}^{+}$ ions is 29

$$
\nu_{j^{i}, X e+}=n_{e} \frac{\sqrt{2}}{3 \sqrt{\pi}}\left(\frac{e^{2}}{4 \pi \epsilon_{0}}\right)^{2} \frac{4 \pi}{\left(e T_{h}\right)^{3 / 2}} \frac{\mu_{j^{i}, X e}^{1 / 2}}{m_{j^{i}}} \ln \Lambda
$$


where the Coulomb logarithm for mixed ion-ion collisions is $^{29}$

$\ln \Lambda_{i i^{\prime}}=23-\ln \left[1 \times 10^{-3} \frac{Z Z^{\prime}\left(m+m^{\prime}\right)}{m T_{i^{\prime}}+m^{\prime} T_{i}}\left(\frac{n_{i} Z^{2}}{T_{i}}+\frac{n_{i^{\prime}} Z^{\prime 2}}{T_{i^{\prime}}}\right)^{1 / 2}\right]$.

We assumed that all ions are singly charged, i.e., $Z=Z^{\prime}=1$, the minor species ions have thermalized with the $\mathrm{Xe}^{+}$ions, i.e., $T_{i} \approx T_{i^{\prime}}$, the $\mathrm{Xe}^{+}$density is much greater than the minor species ion density, i.e., $n_{i^{\prime}} \gg n_{i}$, and $n_{e}=n_{i}$ is the plasma density.

Neutral-neutral collisions. The frequency for collisions between two neutral species is given by ${ }^{30}$

$$
\nu_{j^{n}, X e}=n_{X e} Q \sqrt{\frac{8 e T_{h}}{\pi \mu_{j^{n}, X e}}},
$$

where $Q=\pi \sigma_{j k}^{2} \Omega_{j k}$ is the scattering cross section for a binary gas mixture ${ }^{31}$ and $\sigma_{j k}$ is estimated by averaging the collision diameter of each species. The collision integral for the Lennard-Jones interaction potential, $\Omega_{j k}$, is expressed using the empirical $\mathrm{fit}^{31}$

$$
\Omega_{j k}=A\left(T^{*}\right)^{-B}+C e^{-D T^{*}}+E e^{-F T^{*}}+G e^{-H T^{*}},
$$

where $T^{*}=e T / \varepsilon_{j k}$ for $T$ in $\mathrm{eV}$ and $\varepsilon_{j k}=\sqrt{\varepsilon_{j} \varepsilon_{k}}$.

The values of the Lennard-Jones parameters, $\sigma$ and $\varepsilon$, used here for oxygen and xenon are: $\sigma_{O_{2}}=3.467 \AA$, $\sigma_{O}=3.050 \AA, \sigma_{X e}=4.047 \AA, \varepsilon_{O_{2}} / k=\varepsilon_{O} / k=106.7 \mathrm{~K}$, and $\varepsilon_{X e} / k=231.0 \mathrm{~K}^{31,32}$ The $\mathrm{Ba}-\mathrm{Xe}$ scattering cross section was taken to be constant at $Q_{B a-X e}=40 \AA^{2}$ based on diffusion measurements of $\mathrm{Ba}$ in Xe. ${ }^{15,33}$ The scattering cross section for $\mathrm{BaO}-\mathrm{Xe}$ collisions was calculated as $100.64 \AA^{2}$ using the hard-sphere model ${ }^{30}$

$$
Q_{B a O-X e}=\pi\left(r_{B a O}+r_{X e}\right)^{2},
$$

where $r$ is the van der Waals radius. The radius of the $\mathrm{BaO}$ molecule was taken to be half that of the sum of the bond length and the atomic radii of $\mathrm{Ba}$ and $\mathrm{O}$.

Ion-neutral collisions. During ion-neutral scattering, a dipole moment may be induced in the neutral particle by the ion's electric field. The induced dipole moment exerts a force on the incoming particle, which leads to Langevin polarization capture. ${ }^{34}$ The Langevin cross section is given by

$$
\sigma_{L}=\pi b^{2}=\sqrt{\frac{\pi \alpha_{p} e^{2}}{\epsilon_{0} \mu v_{\mathrm{rel}}^{2}}}
$$

where $\alpha_{p}$ is the polarizability of a neutral atom or molecule, $\mu$ is the reduced mass of the pair, and $v_{\text {rel }}$ is the relative velocity between the two particles. ${ }^{34}$ For interactions with molecules that have a permanent dipole ${ }^{34,35}$ the Langevin cross section is enhanced and the resulting collision frequency can be expressed as

$$
\nu_{L}=n\left[\sqrt{\frac{\pi \alpha_{p} e^{2}}{\epsilon_{0} \mu}}+c \frac{q \mu_{D}}{\sqrt{2 \pi \epsilon_{0}^{2} \mu e T}}\right]
$$

where $c$ is a parameter between 0 and 1 that accounts for the effectiveness of the ion locking in the dipole, i.e., $c=0$ corresponds to free rotation of the dipole and $c=1$ corresponds to a locked dipole where $\theta=0$ with respect to the vector between the two particles. ${ }^{35,36}$ The dipole moment, $\mu_{D}$, is calculated as the product of the total positive or negative charge and the distance between the charge centroids. The $\mathrm{BaO}$ dipole moment was calculated to be $8.843 \times 10^{-29} \mathrm{C} \cdot \mathrm{m}$ for a Ba-O bond length of $2.76 \AA{ }^{37}$ Note that $\mathrm{O}_{2}$ does not have a permanent dipole moment as the molecule is symmetric. Values for the polarizability of various atomic and molecular species of interest to this work can be found in the CRC Handbook of Chemistry and Physics. ${ }^{38}$

Charge exchange processes between $\mathrm{Xe}$ and $\mathrm{O}_{2}$ are considered here because their ionization potentials are simi$\operatorname{lar}\left(\Phi_{X e}=12.13 \mathrm{eV}\right.$ and $\left.\Phi_{O_{2}}=12.07 \mathrm{eV}\right)$. Since cross section data for $\mathrm{Xe}^{+}+\mathrm{O}_{2}$ and $\mathrm{O}_{2}^{+}+\mathrm{Xe}$ charge exchange are not available, these processes are respectively modeled as $\mathrm{O}_{2}^{+}+\mathrm{O}_{2}$ and $\mathrm{Xe}^{+}+\mathrm{Xe}$ resonant charge exchange.

$\mathrm{Xe}^{+}+\mathrm{O}_{2}$ charge exchange is described using $\mathrm{O}_{2}^{+}+\mathrm{O}_{2}$ cross section data from Stebbings et al. ${ }^{39}$ The data are extrapolated to lower energies using the following equation from Rapp and Francis valid for ion energies greater than $0.052 \mathrm{eV}:^{40}$

$$
\sigma=\left(-k_{1} \ln v+k_{2}\right)^{2}
$$

where $k_{1}$ and $k_{2}$ are fit constants. $\mathrm{O}_{2}^{+}+\mathrm{Xe}$ charge exchange is described using $\mathrm{Xe}^{+}+\mathrm{Xe}$ cross section data from Miller et al. ${ }^{41}$

Xenon has a larger polarizability than $\mathrm{O}_{2}\left(\alpha_{p}=4.044\right.$ $\AA^{3}$ for Xe (Ref. 38) compared with $\alpha_{p}=1.57 \AA^{3}$ for $\mathrm{O}_{2}$ (Ref. 34)), and therefore, the charge exchange cross sections for $\mathrm{O}_{2}^{+}+\mathrm{Xe}$ charge exchange should be higher than the reverse reaction. The $\mathrm{Xe}^{+}+\mathrm{Xe}$ charge exchange cross sections are approximately twice as large as the $\mathrm{O}_{2}^{+}+\mathrm{O}_{2}$ charge exchange cross sections. Charge exchange between $\mathrm{Xe}^{+}$and $\mathrm{O}$ was not considered here as the reaction is endothermic and has an energy defect of $1.49 \mathrm{eV}$. The rate constant for these charge exchange collisions is small for the heavy particle temperatures in the cathode. ${ }^{34}$

Chemical reactions. $\mathrm{BaO}$ and $\mathrm{O}$ are generated via reactions between $\mathrm{Ba}$ and $\mathrm{O}_{2}$ according to the reaction

$$
\mathrm{Ba}+\mathrm{O}_{2} \rightarrow \mathrm{BaO}+\mathrm{O}, \quad \Delta H_{R}^{\circ}=-0.557 \mathrm{eV} .
$$

The rate constant for this reaction was measured by Kashireninov et al., for temperatures between 970 and $1180 \mathrm{~K}$ and is fit to an Arrhenius equation. ${ }^{42}$ The rate constant is extrapolated out to typical cathode operating temperatures. Ionneutral collisions may also occur, and the most favorable reactions for $\mathrm{Ba}^{+}$reacting with $\mathrm{O}_{2}$ and $\mathrm{Ba}$ reacting with $\mathrm{O}_{2}^{+}$are

$$
\begin{gathered}
\mathrm{Ba}^{+}+\mathrm{O}_{2} \rightarrow \mathrm{BaO}^{+}+\mathrm{O}, \Delta H_{R}^{\circ}=1.143 \mathrm{eV}, \\
\mathrm{Ba}+\mathrm{O}_{2}^{+} \rightarrow \mathrm{BaO}^{+}+\mathrm{O}, \Delta H_{R}^{\circ}=-5.717 \mathrm{eV} .
\end{gathered}
$$

Since the reaction in Eq. (25) is exothermic, we assume that the reaction proceeds to completion every time $\mathrm{Ba}$ and $\mathrm{O}_{2}^{+}$collide. Therefore, the reaction rate constant for Eq. (25) 
is assumed to be equal to the Langevin rate constant. The cross sections for the reaction given in Eq. (24) have been measured by Murad. ${ }^{43}$ The reverse reactions for Eqs. (23)-(25) are not considered here as the densities of $\mathrm{BaO}$ and $\mathrm{O}$ are much smaller than the densities of $\mathrm{Ba}$ and $\mathrm{O}_{2}$. Note that the dissociation energy of $\mathrm{O}_{2}$ is $5.12 \mathrm{eV},{ }^{44}$ and the dissociation energy of $\mathrm{BaO}$ is $5.42 \mathrm{eV}^{45}$ Since these energies are relatively high, dissociation of these molecules will be neglected in this work.

\section{BOUNDARY CONDITIONS}

The computational domain has five boundary surfaces: the upstream inlet, emitter surface, orifice plate, orifice, and centerline. The net flux, defined as $\boldsymbol{\Gamma}_{\text {net }}=\boldsymbol{\Gamma}_{\text {in }}+\boldsymbol{\Gamma}_{\text {out }}$, is prescribed at each boundary, where $\boldsymbol{\Gamma}_{\text {in }}$ and $\boldsymbol{\Gamma}_{\text {out }}$ refer to the flux into and out of the plasma control volume, respectively. The direction of the flux vectors and a summary of the boundary conditions are shown in Fig. 1. $\mathrm{Ba}$ and $\mathrm{BaO}$ are introduced into the gas via evaporation from the emitter pores, and ions are generated via electron impact ionization. $\mathrm{O}_{2}$ enters the plasma control volume with the Xe gas through the upstream inlet, and $\mathrm{O}, \mathrm{O}^{+}$, and $\mathrm{O}_{2}^{+}$are generated inside the plasma discharge. A detailed discussion of the boundary conditions at each surface is presented below.

Upstream inlet to the cathode. This boundary is a source of $\mathrm{O}_{2}$, which enters the cathode with the Xe gas. To model an $\mathrm{O}_{2}$ concentration of $100 \mathrm{ppm}$, it is assumed that $\mathrm{O}_{2}$ enters the plasma control volume at the Xe neutral velocity and that the $\mathrm{O}_{2}$ flux is four orders of magnitude lower than the Xe neutral flux. This boundary serves as a sink for all other minor species, and it is assumed that these species flow out of the plasma control volume and upstream across this boundary at the thermal velocity.

Emitter surface. Gaseous $\mathrm{Ba}$ and $\mathrm{BaO}$ are generated in the emitter via reactions between the impregnant material and the tungsten matrix. These products then flow through the emitter pores and enter the plasma control volume across this boundary. The supply rate of $\mathrm{Ba}$ and $\mathrm{BaO}$ is driven by the difference between the pressure at the reaction front and the partial pressure at the surface. ${ }^{14}$ During cathode operation, the insert pores become depleted of Ba over time and the reaction front recedes further into the pores, thus increasing the distance through which these species must flow to reach the surface. Therefore, the arrival rate of Ba to the surface must also depend on the depletion depth and subsequently, the operating time.

Roquais et $a l .{ }^{46}$ measured the Ba depletion depth with time for vacuum dispenser cathodes containing impregnant with a 4:1:1 molar ratio of $\mathrm{BaO}, \mathrm{CaO}$, and $\mathrm{Al}_{2} \mathrm{O}_{3}$ over a range of temperatures and developed a relation for the flux of $\mathrm{Ba}$ through the pores using kinetic theory. Polk et al. ${ }^{14}$ used these data to derive an expression for the Ba supply flux in plasma cathodes by modifying Roquais' relation to account for the Ba partial pressure at the surface and the difference in the effective mean free paths for the two cathodes, which have different porosity. The Ba supply flux used here is that given by Polk et al.

$$
\Gamma_{s, B a}=\frac{\Gamma_{s, B a}^{R}}{C}\left(\frac{P_{v}-P_{B a}}{P_{v}}\right),
$$

where $\Gamma_{s, B a}^{R}$ is the Ba supply flux derived by Roquais for vacuum cathodes given by

$$
\Gamma_{s, B a}^{R}=\frac{4}{3} \frac{\lambda_{\mathrm{eff}, \mathrm{R}}}{\left(2 \pi m_{B a} k T\right)^{1 / 2}} \frac{P_{v}}{\delta},
$$

and $\lambda_{\text {eff }}$ is the effective mean free path of the particles accounting for geometric factors, $C=\lambda_{\text {eff }, \mathrm{R}} / \lambda_{\mathrm{eff}, \mathrm{HC}}=1.2{ }^{14}$ $\delta$ is the depletion depth, $P_{v}$ is the Ba vapor pressure, and the pressure gradient is approximated by $P_{v} / \delta$.

It has been observed that the evaporants from a 4:1:1 dispenser cathode consist of a molar ratio of $\mathrm{Ba}$ to $\mathrm{BaO}$ of 13.3:1, ${ }^{47}$ and therefore, the supply rate of $\mathrm{BaO}$ from the emitter surface is taken to be $\Gamma_{s, B a O}=\Gamma_{s, B a} / 13.3$. It has been shown that the build-up of multiple Ba layers is unstable at normal cathode operating temperatures, ${ }^{48}$ and therefore, the emitter surface is assumed to be in steady state so that no $\mathrm{Ba}$ or $\mathrm{BaO}$ are allowed to accumulate on the surface. Ions leave the plasma control volume at the Bohm velocity. The ions then recombine at the surface and leave as neutrals at the thermal velocity. No ions are released from the surface back into the gas; therefore, the net ion flux of $\mathrm{Ba}^{+}$and $\mathrm{BaO}^{+}$at the emitter surface is: $\boldsymbol{\Gamma}_{i}=n_{i}\left(\frac{k T_{e}}{m_{i}}\right)^{1 / 2} \hat{\mathbf{r}}$.

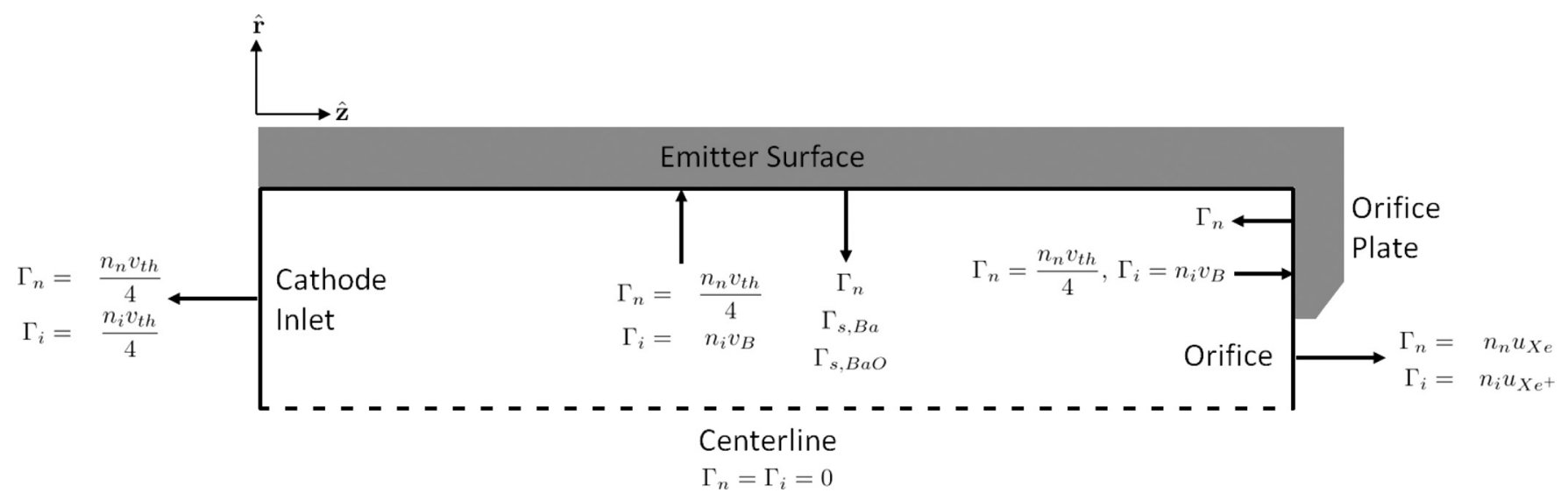

FIG. 1. Diagram of the transport model boundary conditions. 
Since the surface is in steady state, the total flux of $\mathrm{Ba}$ and $\mathrm{BaO}$ must be zero at the surface. Therefore, the flux of $\mathrm{Ba}$ and $\mathrm{BaO}$ to the surface (either through the pores or via adsorption from the gas phase) must be balanced by desorption of these species from the surface and the net neutral flux at the surface is: $\boldsymbol{\Gamma}_{n}=-\left[n_{i}\left(\frac{k T_{e}}{m_{n}}\right)^{1 / 2}+\Gamma_{s, n}\right] \hat{\mathbf{r}}$. If the reactions supplying $\mathrm{Ba}$ and $\mathrm{BaO}$ are inhibited, the net neutral flux simply balances the ion flux to the surface.

The oxygen behaves differently than $\mathrm{Ba}$ and will deposit on the emitter surface until it is saturated and can no longer accumulate additional oxygen. Therefore, the emitter boundary conditions change over time from a largely absorbing surface to a nonabsorbing surface once steady state is reached. To understand the gas phase dynamics, two bounding cases are considered here. First, we consider the case in which there is no accumulation of oxygen on the emitter surface and the emitter surface is assumed to be in steady state. Ions leave the plasma control volume and strike these surfaces at the Bohm velocity where they recombine and leave as neutrals.

Second, we consider that the emitter surface is perfectly absorbing, i.e., all oxygen ions and neutrals that reach the surface remain on the surface. This case is referred to as the perfectly absorbing boundary condition. The emitter surface is no longer assumed to be in steady state, and any oxygen that strikes the surface is allowed to accumulate on the surface without bound. Oxygen ions leave the plasma control volume and strike the emitter surface at the Bohm velocity. The ions are completely absorbed by the surface, and none are released back into the plasma. Oxygen neutrals are assumed to leave the plasma control volume and strike the emitter surface at the thermal velocity.

Orifice plate. The orifice plate is a non-emitting surface and is assumed to be in steady state so that no particles are allowed to accumulate on the surface. Ions leave the plasma control volume at the Bohm velocity. The ions then recombine at the surface and leave as neutrals-no ions are released from the surface back into the gas. Since the surface is in steady state, the total flux of each species must be zero at the surface, and thus, $\boldsymbol{\Gamma}_{n}=-\boldsymbol{\Gamma}_{i}$.

Cathode orifice. It is assumed that all neutrals flow out of the plasma control volume through the cathode orifice at the Xe neutral velocity and that all ions flow out of the plasma control volume at the $\mathrm{Xe}^{+}$ion velocity. The solution appears to be relatively insensitive to changes in this boundary condition, with the exception of $\mathrm{BaO}$ neutrals. In Polk's version of the transport model, the neutrals are assumed to flow out of the plasma control volume through the cathode orifice at the thermal velocity. ${ }^{15}$ Imposing this boundary condition for $\mathrm{BaO}$ causes steep gradients in the $\mathrm{BaO}$ neutral densities near the orifice, which is unphysical. Modifying this boundary condition so that all neutrals leave at the Xe neutral velocity does not significantly alter the results of Polk's barium simulation since the barium density is so low near the orifice.

Centerline. This is a symmetry boundary and the ion and neutral fluxes are set to zero: $\boldsymbol{\Gamma}_{i}=\boldsymbol{\Gamma}_{n}=0 \hat{\mathbf{r}}$.

\section{TRANSPORT MODEL SOLUTION}

Mikellides et al. have developed a two-dimensional numerical model of the weakly ionized, highly collisional xenon plasma inside the hollow cathode emitter region that is described elsewhere. ${ }^{16-18}$ The computational mesh is axisymmetric about $r=0$ with a length of $2 \mathrm{~cm}$ and an inner radius of $0.189 \mathrm{~cm}$. The transport model was run for a discharge current of $15 \mathrm{~A}$ and a xenon flow rate of $3.7 \mathrm{sccm}$. The solution to the xenon plasma model at these conditions shows that the cathode generates a high density, low temperature plasma. The results are shown in Fig. 2 and are briefly discussed here. Note that the light gray region between $r=0.189$ and $r=0.27 \mathrm{~cm}$ shown in Fig. 2 represents the emitter surface, and the dark gray region above $r=0.27 \mathrm{~cm}$ represents the outer cathode tube, which houses the porous tungsten emitter.

Neutral Xe enters the cathode through the upstream boundary and accelerates through the orifice as shown by the Xe neutral density contours and streamlines in Fig. 2(a). The density decreases near the downstream end of the computational region as neutrals exit through the orifice or become ionized. Most of the ionization occurs in regions where electron temperatures are highest. Figure 2(b) shows the electron temperatures and electron current streamlines. Electrons are thermionically emitted from the insert surface, and electrons emitted between $\mathrm{z}=1.6$ and $2.5 \mathrm{~cm}$ escape through the orifice, while electrons emitted at axial locations of $z<1.6$ $\mathrm{cm}$ move further upstream where the plasma potential is lower. A more detailed description of the plasma in this cathode under similar operating conditions is described by Mikellides et al. ${ }^{16,18}$

High plasma densities occur between $z=1.9$ and $2.2 \mathrm{~cm}$ as shown in Fig. 2(c). Ions flow radially out of this region and either strike the insert surface or escape through the orifice or upstream inlet. Ions that strike the insert surface recombine and are reemitted as neutrals. This process accounts for the neutral xenon streamlines seen to originate at the emitter surface in Fig. 2(a). Figure 2(d) shows plasma potential contours and ion current streamlines.

The transport model was initially solved considering only $\mathrm{Ba}$ and $\mathrm{BaO}$ in the background Xe plasma and was run until the $\mathrm{Ba}$ and $\mathrm{BaO}$ species densities reached equilibrium. At this point, oxygen was allowed to enter the upstream inlet and the model was run considering the two bounding cases for the emitter surface boundary conditions. The solution to the $\mathrm{Ba} / \mathrm{BaO}$ transport model was unchanged by the addition of oxygen in the discharge.

Ba neutrals are supplied from the emitter interior, evaporate from the emitter surface, and enter the discharge as shown in Fig. 3(a). Neutrals that are emitted from the insert at axial locations of $z<1 \mathrm{~cm}$ escape through the upstream inlet, and neutrals emitted from the surface downstream of $z=1 \mathrm{~cm}$ are swept into the ionization zone by the neutral xenon flow and are ionized before they can escape through the orifice exit. A low density region encompassing the last $10 \mathrm{~mm}$ of the insert forms as a result of intense ionization of $\mathrm{Ba}$, which has a relatively low ionization potential of $5.2 \mathrm{eV}$. The mean free path for $\mathrm{Ba}$ ionization in this region is 


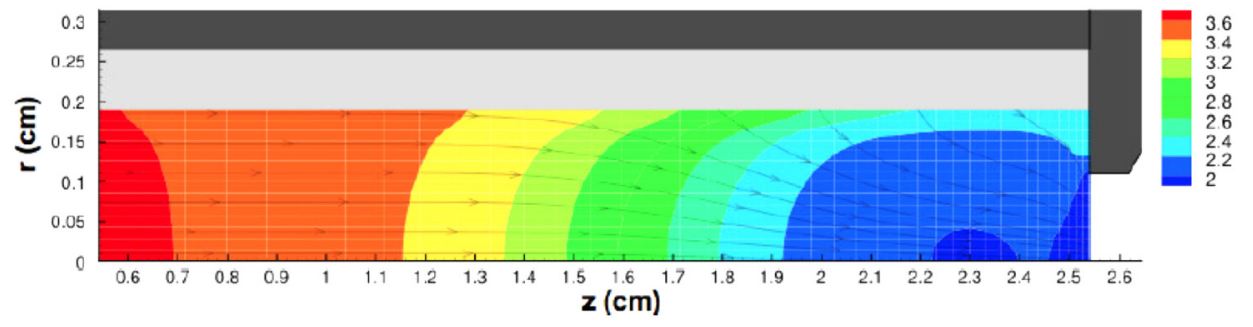

(a)Xe neutral density, $n_{n}\left(10^{21} \mathrm{~m}^{-3}\right)$, with neutral streamlines

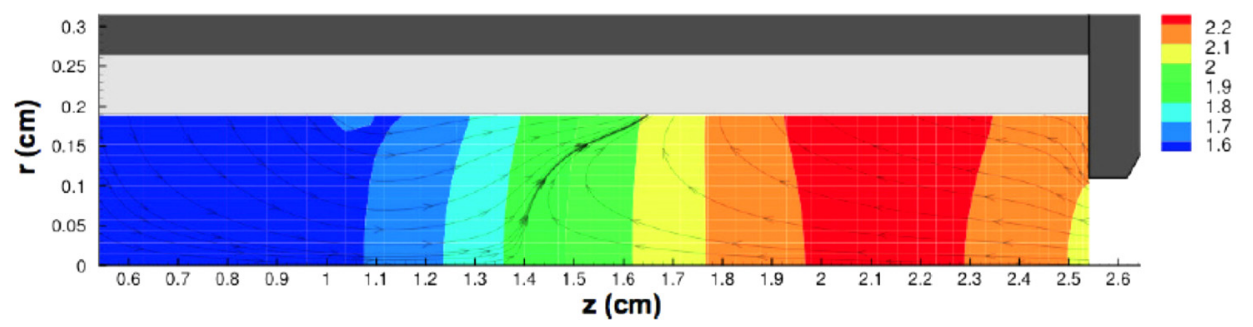

(b)Electron temperature, $T_{e}(\mathrm{eV})$, with electron current streamlines

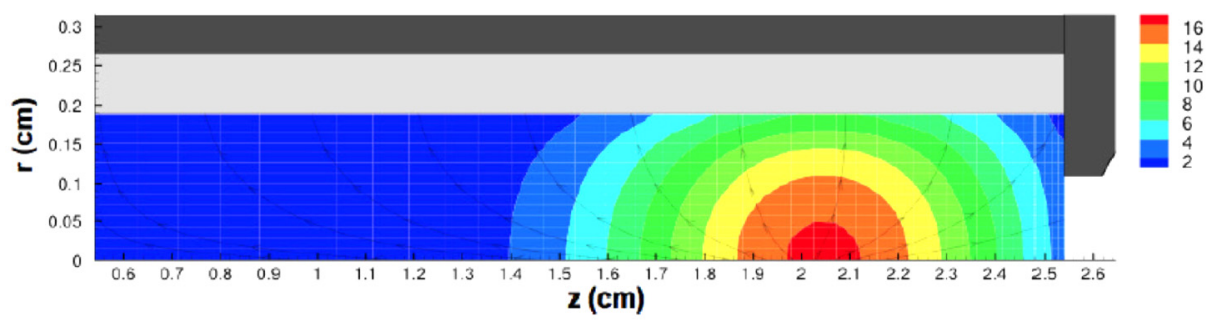

(c)Plasma density, $n_{e}\left(10^{19} \mathrm{~m}^{-3}\right)$, with ion current streamlines

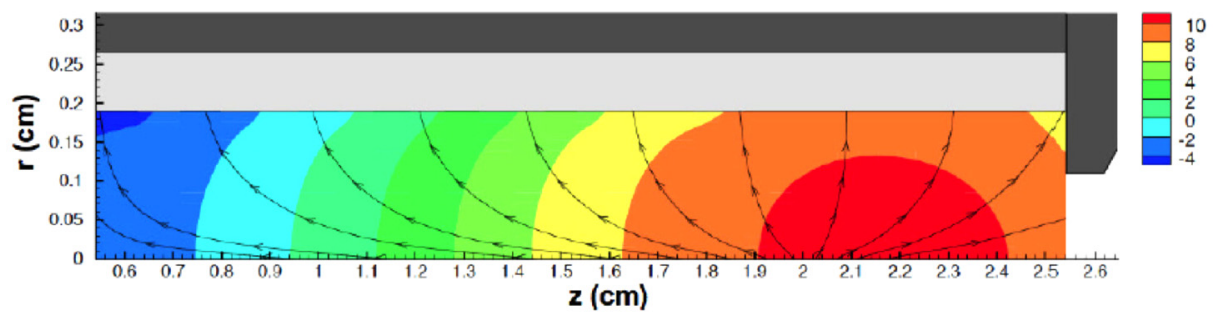

FIG. 2. Xenon plasma solution for a discharge current of $15 \mathrm{~A}$ and a Xe flow rate of $3.7 \mathrm{sccm}$.

(d)Plasma potential, $\phi(\mathrm{V})$, with ion current streamlines

approximately $0.2 \mathrm{~mm}$ as shown in Fig. 4(a). Note that the ionization region for barium coincides with the high plasma density region shown in Fig. 2(c) as expected. Figure 3(b) shows the $\mathrm{Ba}^{+}$ion density contours and streamlines. The $\mathrm{Ba}^{+}$ions formed in the ionization zone are pushed back to the surface via the electric field.

$\mathrm{BaO}$ neutrals evaporate from the emitter, enter the discharge, and are pushed downstream by the Xe neutral gas flow as shown in Fig. 3(c). The dominant process for producing $\mathrm{BaO}^{+}$is via electron impact ionization of $\mathrm{BaO}$, and very little $\mathrm{BaO}^{+}$is generated by reactions between barium and oxygen as the densities of these species are relatively low. The $\mathrm{BaO}$ ionization rate constant is approximately an order of magnitude lower than the rate constant for $\mathrm{Ba}$ ionization, and the ionization potential for $\mathrm{BaO}$ is $6.9 \mathrm{eV}$. Therefore, Fig. 3(c) shows that some $\mathrm{BaO}$ escapes ionization and exits the cathode through the orifice. Some $\mathrm{BaO}$ does get ionized and is transported back to the surface in the same way that $\mathrm{Ba}^{+}$ions are. Figure 3(d) shows the $\mathrm{BaO}$ ion density contours and streamlines. The $\mathrm{BaO}$ mean free path for ionization is approximately $3 \mathrm{~mm}$ as shown in Fig. 4(b).

The terms in the expression for momentum conservation given in Eq. (5) are plotted in Fig. 5 along the axis of symmetry, i.e., for $r=0$. In the solution for $\mathrm{Ba}^{+}$and $\mathrm{BaO}^{+}$ shown in Figs. 5(a) and 5(c), the two dominant terms are the electric field and the $\mathrm{Xe}^{+}$ion drag. The convective acceleration term, $n m(\mathbf{u} \cdot \nabla) u_{z}$, which appears on the left-hand side of Eq. (5) is much smaller than the other terms. Therefore, 


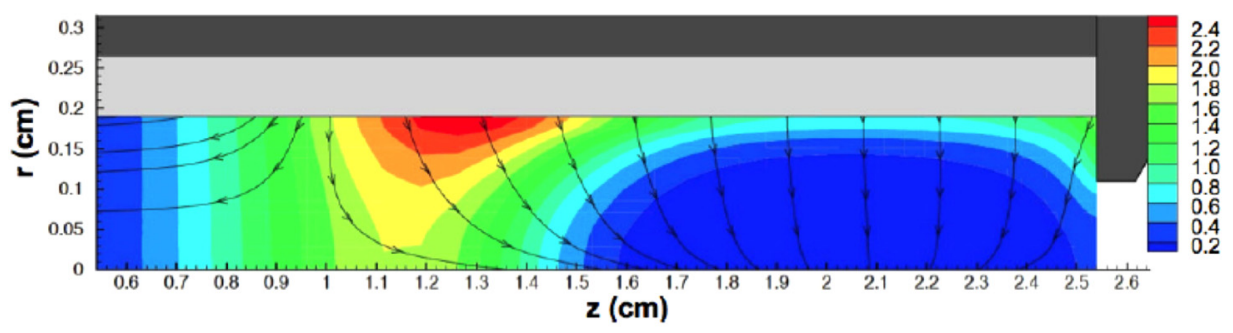

(a)Ba neutral density, $n_{B a}\left(10^{16} \mathrm{~m}^{-3}\right)$, and Ba streamlines.

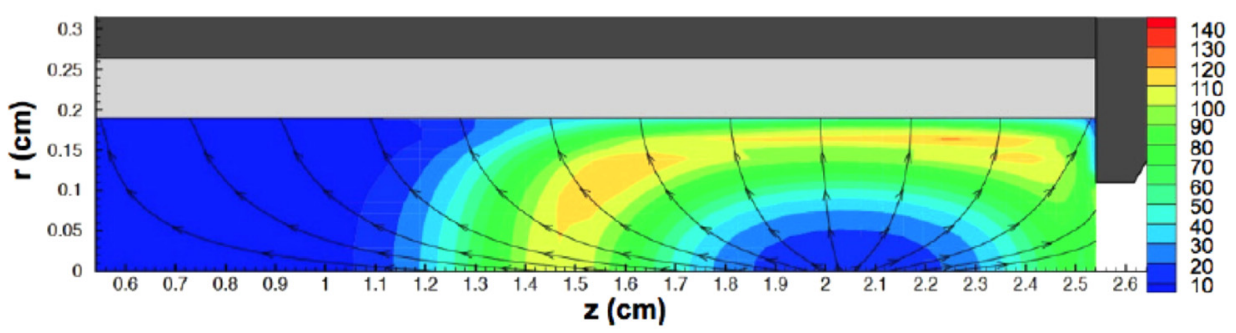

(b) $\mathrm{Ba}^{+}$ion density, $n_{\mathrm{Ba}}\left(10^{14} \mathrm{~m}^{-3}\right)$, and $\mathrm{Ba}^{+}$streamlines.

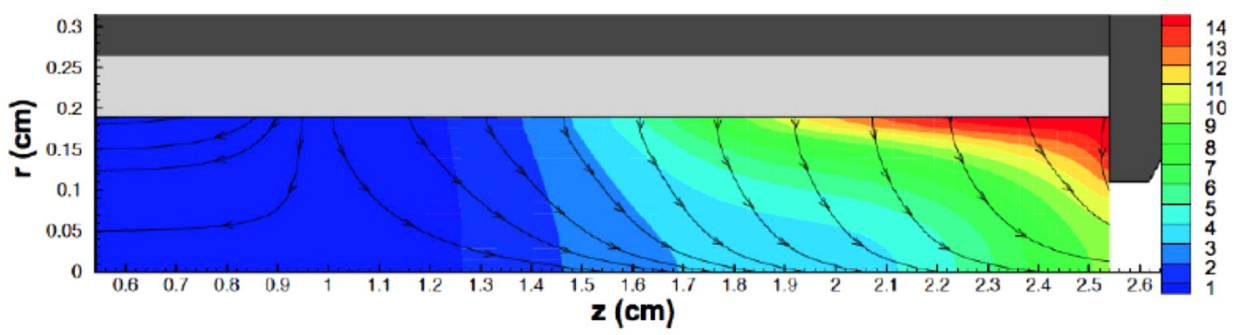

(c) $\mathrm{BaO}$ neutral density, $n_{\mathrm{BaO}}\left(10^{14} \mathrm{~m}^{-3}\right)$, and $\mathrm{BaO}$ streamlines.

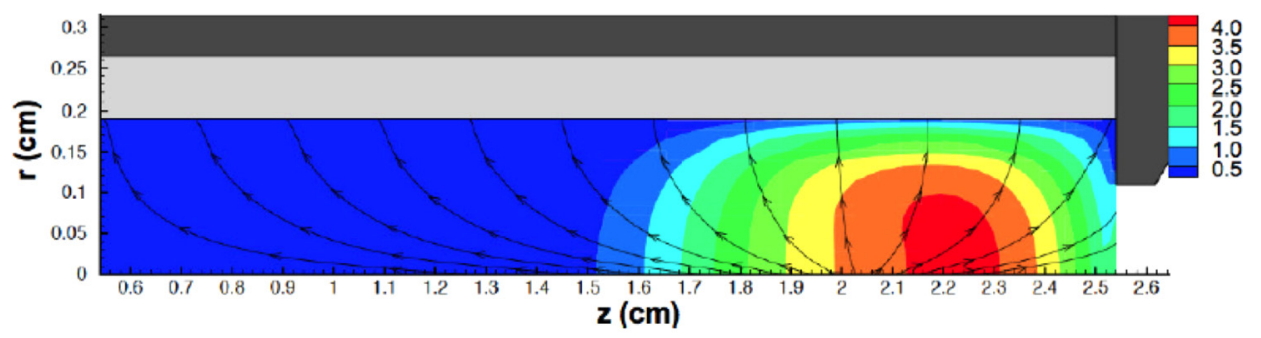

(d) $\mathrm{BaO}^{+}$ion density, $n_{\mathrm{BaO}}+\left(10^{14} \mathrm{~m}^{-3}\right)$, and $\mathrm{BaO}^{+}$streamlines.
FIG. 3. $\mathrm{Ba}$ and $\mathrm{BaO}$ plasma solution for a discharge current of $15 \mathrm{~A}$ and a Xe flow rate of $3.7 \mathrm{sccm}$.

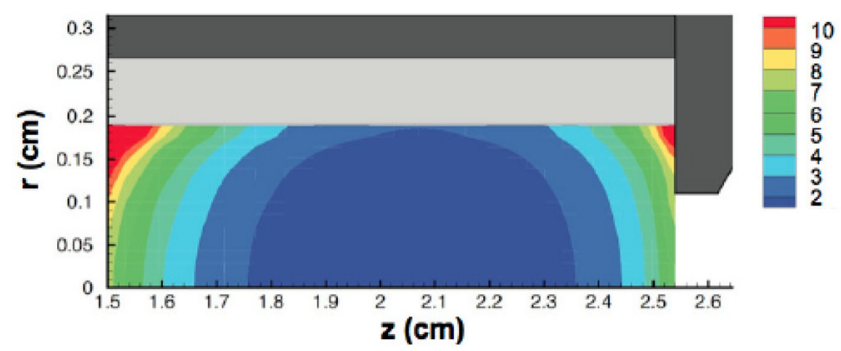

(a)Ba ionization mean free path, $\lambda_{\mathrm{mfp}}\left(10^{-4} \mathrm{~m}\right)$.

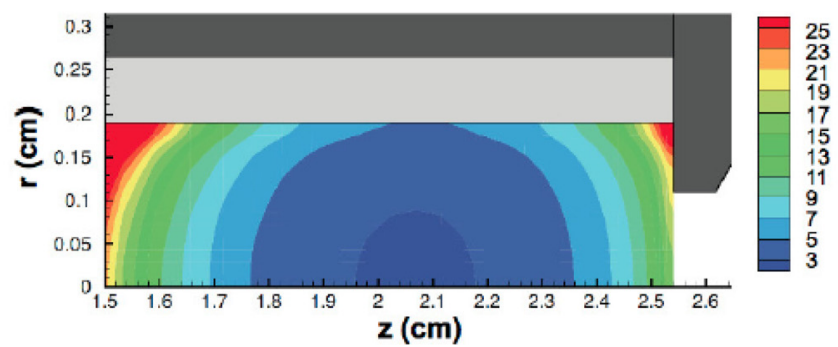

(b) $\mathrm{BaO}$ ionization mean free path, $\lambda_{\mathrm{mfp}}\left(10^{-3} \mathrm{~m}\right)$.

FIG. 4. Ionization mean free path of $\mathrm{Ba}$ and $\mathrm{BaO}$ for a discharge current of $15 \mathrm{~A}$ and a Xe flow rate of $3.7 \mathrm{sccm}$. 


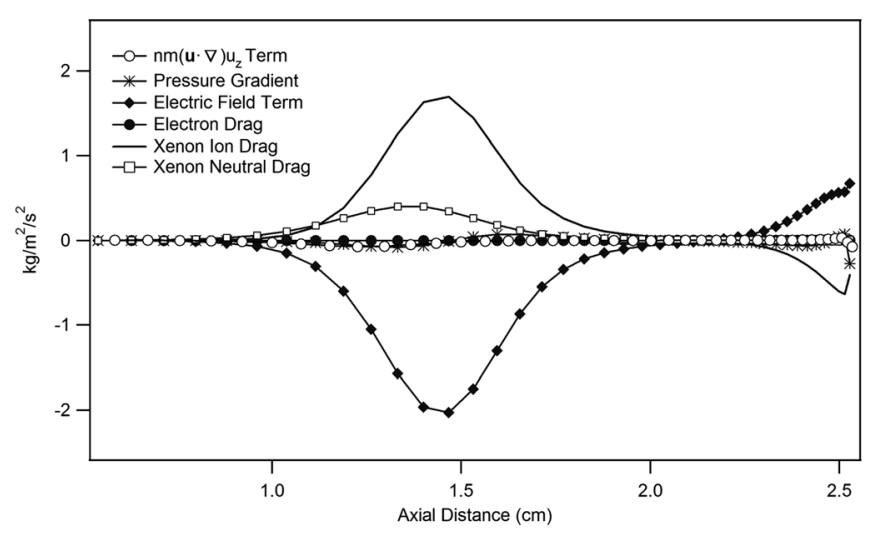

(a) Comparison $\mathrm{Ba}^{+}$momentum terms

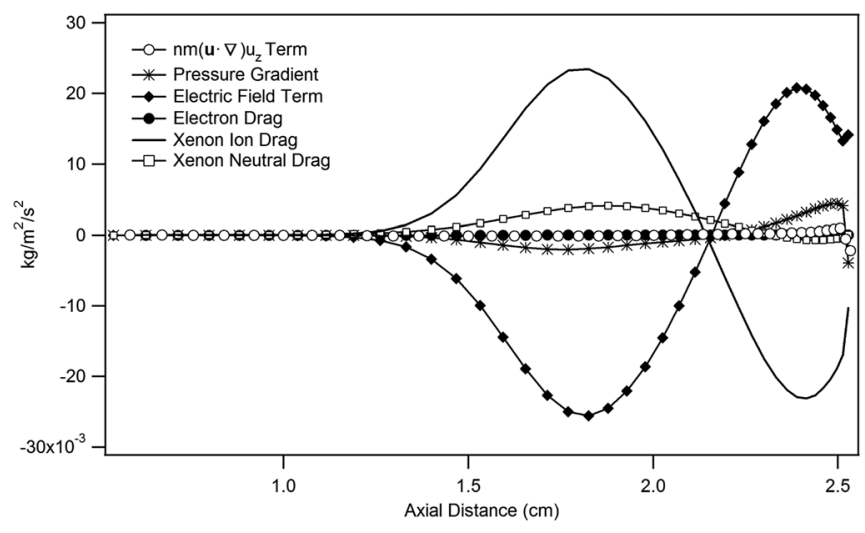

(c) Comparison of $\mathrm{BaO}^{+}$momentum terms

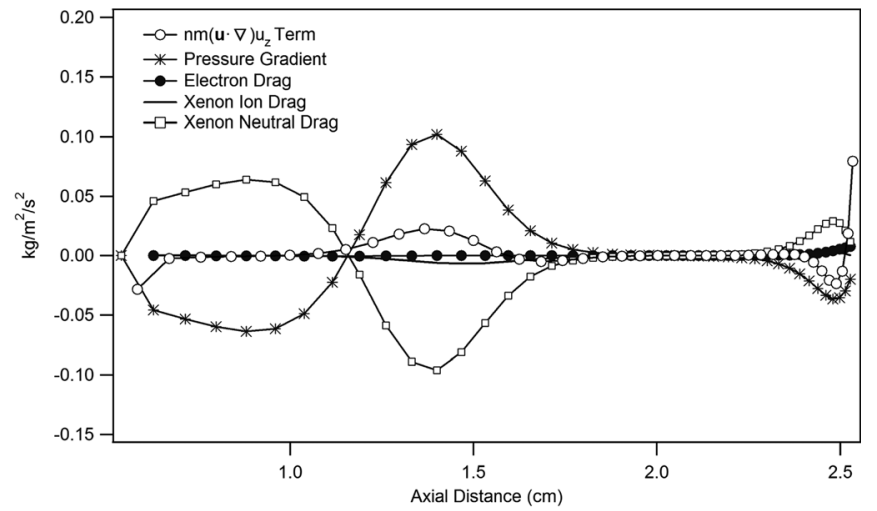

(b) Comparison of Ba momentum terms

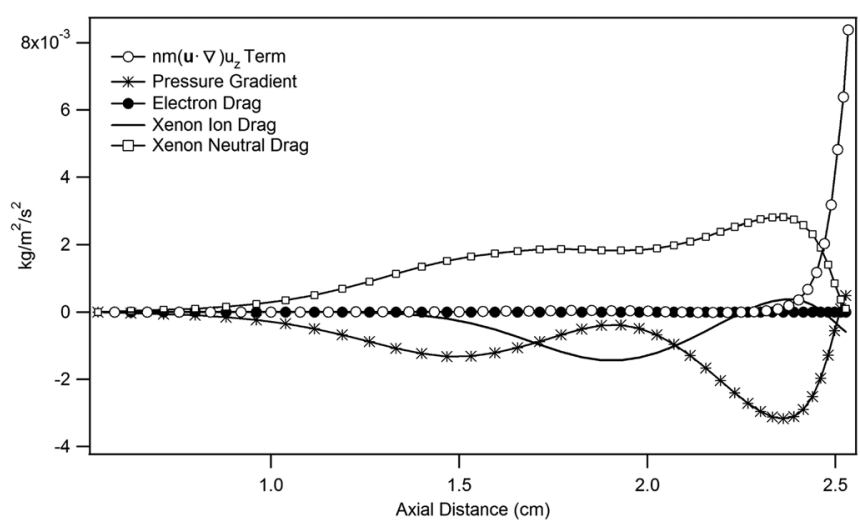

(d) Comparison of $\mathrm{BaO}$ momentum terms

FIG. 5. Comparison of the terms in the momentum equation given in Eq. (5) along the axis of symmetry $(r=0)$.

the assumption to neglect this term in the transport model is justified.

In the solution for neutral $\mathrm{Ba}$ and $\mathrm{BaO}$ shown in Figs. 5(b) and 5(d), the Xe neutral drag and the pressure gradient are the two dominant terms throughout much of the discharge. The convective acceleration term dominates at the orifice where the velocities increase, but is small everywhere else in the discharge. For the purpose of this work, which is primarily to understand the dynamics that occur in the discharge upstream of the orifice, it is safe to neglect this term.

In the $\mathrm{BaO}$ solution, the $\mathrm{Xe}^{+}$ion drag term is also important and becomes large at axial locations near $z=2 \mathrm{~cm}$. The plasma densities are high in this region, and since $\mathrm{BaO}$ has a high polarizability and a permanent dipole, the frequency for $\mathrm{Xe}^{+}-\mathrm{BaO}$ collisions is high at these locations. Note that electron drag acting on $\mathrm{BaO}$ was not included in the model because of insufficient data to determine the reaction rate. The electron drag term was included in the Ba solution, but is small compared with the other terms in the momentum equation as seen in Fig. 5(b).

Once the $\mathrm{Ba}$ and $\mathrm{BaO}$ densities reach equilibrium, oxygen is allowed to enter the domain through the upstream inlet. The solution to the transport model assuming nonabsorbing boundary conditions for oxygen at the emitter surface is shown in Figs. 6 and 7, and results for the perfectly absorbing boundary condition are shown in Fig. 9.

\section{A. Nonabsorbing case}

In the nonabsorbing case, no oxygen is permitted to accumulate on the surface and so it fills the discharge and reaches an equilibrium value that is relatively constant throughout the computational region. Note the similarity between the $\mathrm{O}_{2}$ neutral density contours for the nonabsorbing case shown in Fig. 6(a) and the Xe neutral density contours shown in Fig. 2(a). The $\mathrm{O}_{2}$ neutral density is everywhere about four orders of magnitude lower than the Xe neutral density, which is consistent with the prescribed oxygen concentration of $100 \mathrm{ppm}$ at the cathode inlet. The density decreases near the downstream end of the computational region as neutrals exit through the orifice or become ionized.

Figure 6(b) shows the $\mathrm{O}_{2}^{+}$density contours and streamlines. Since the only mechanism for $\mathrm{O}_{2}$ ionization considered in the model is charge exchange with $\mathrm{Xe}^{+}$, the ionization rate depends on the plasma density and heavy particle temperature. The results show that the high $\mathrm{O}_{2}^{+}$density region between $z=1.9$ and $2.2 \mathrm{~cm}$ coincides with the high plasma density region as shown in Fig. 2(c) as expected. The mean free path for $\mathrm{O}_{2}$ ionization is approximately $15 \mathrm{~mm}$ in this region as shown in Fig. 7. The ions generated in this zone are transported back toward the insert via the electric field. Ions that hit the emitter surface recombine and leave the 


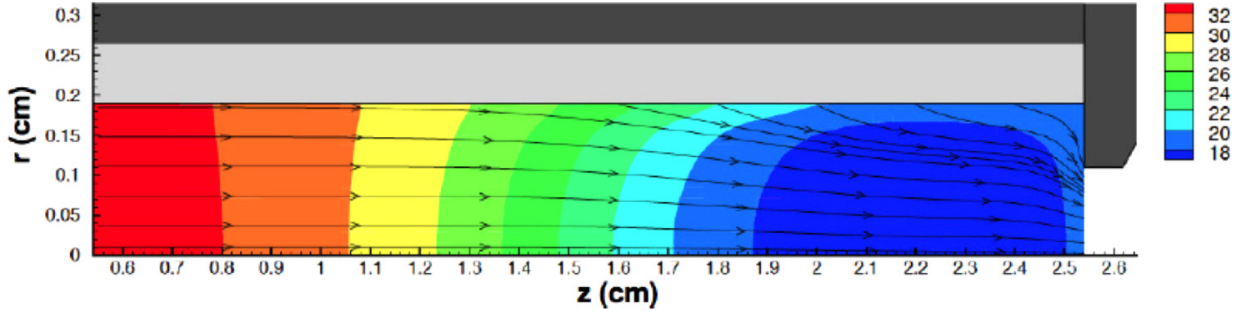

(a) $\mathrm{O}_{2}$ neutral density, $n_{\mathrm{O}_{2}}\left(10^{16} \mathrm{~m}^{-3}\right)$, and $\mathrm{O}_{2}$ streamlines.

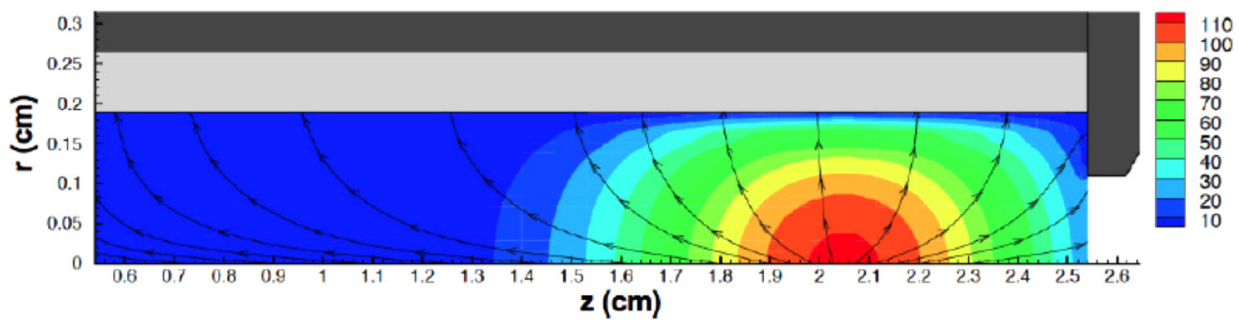

(b) $\mathrm{O}_{2}^{+}$ion density, $n_{\mathrm{O}_{2}^{+}}\left(10^{14} \mathrm{~m}^{-3}\right)$, and $\mathrm{O}_{2}^{+}$streamlines.

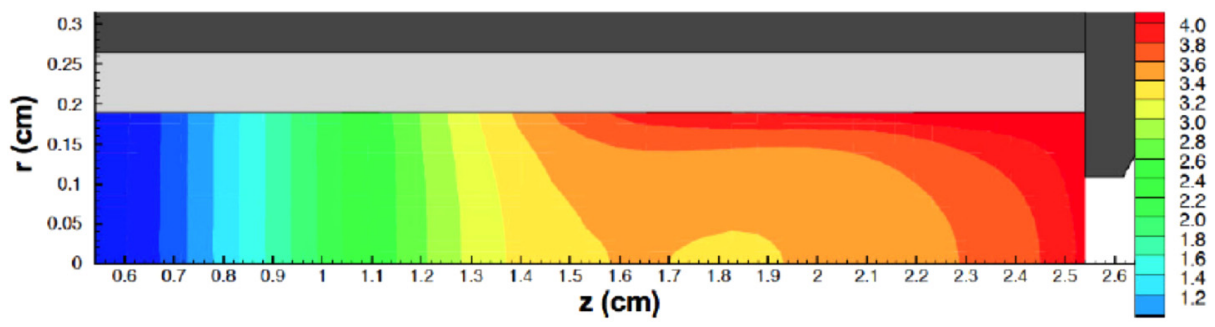

(c)O neutral density, $n_{O}\left(10^{12} \mathrm{~m}^{-3}\right)$.

surface as neutrals. This process accounts for the streamlines originating at the emitter surface in Fig. 6(a).

Figure 6(c) shows the density contours for atomic oxygen. The number density for $\mathrm{O}$ is about five orders of magnitude lower than the number density for $\mathrm{O}_{2}$. Since dissociation of $\mathrm{O}_{2}$ was neglected in this model, the only way to generate $\mathrm{O}$ is via reactions between $\mathrm{Ba}$ and $\mathrm{O}_{2}$.

The terms in the expression for momentum conservation given in Eq. (5) are plotted in Fig. 8 along the axis of symmetry, i.e., for $r=0$. In the solution for neutral $\mathrm{O}_{2}$ and $\mathrm{O}$ shown in Figs. 8(a) and 8(e), the Xe neutral drag and the pressure gradient are the two dominant terms throughout much of the discharge. The convective acceleration term dominates at the orifice where the velocities increase, but is small everywhere else in the discharge. In the $\mathrm{O}_{2}$ solution, the electron drag becomes important as we approach the orifice. In the solution for $\mathrm{O}_{2}^{+}$shown in Fig. 8(c), the two dominant terms are the electric field term and the $\mathrm{Xe}^{+}$ion drag, and the convective acceleration term is much smaller than the other terms.

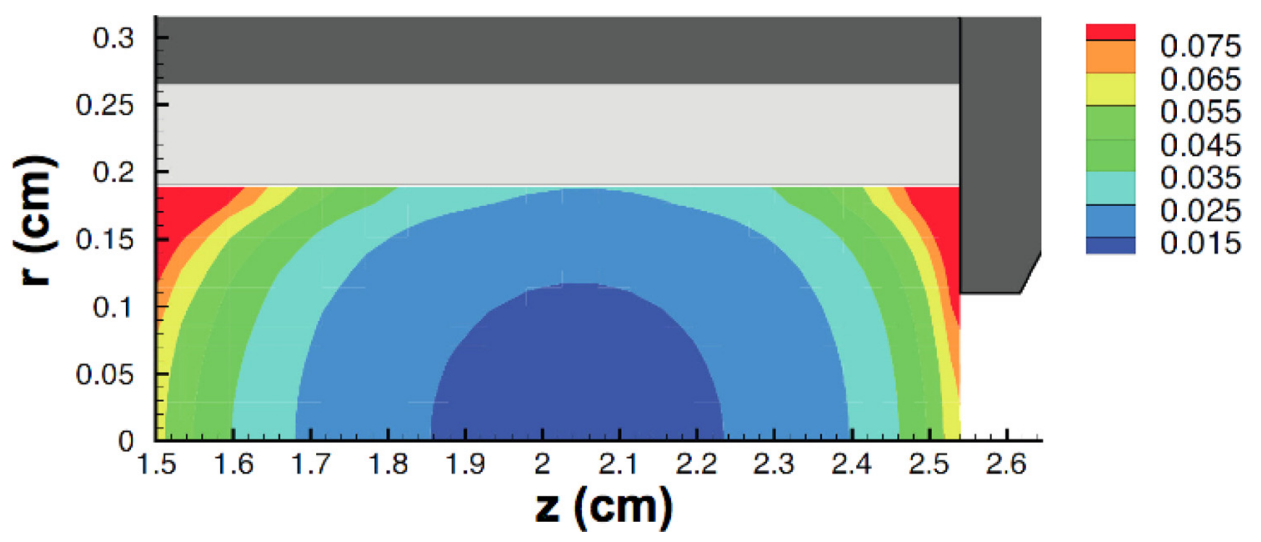

FIG. 7. $\mathrm{O}_{2}$ ionization mean free path, $\lambda_{\mathrm{mfp}}(\mathrm{m})$. 


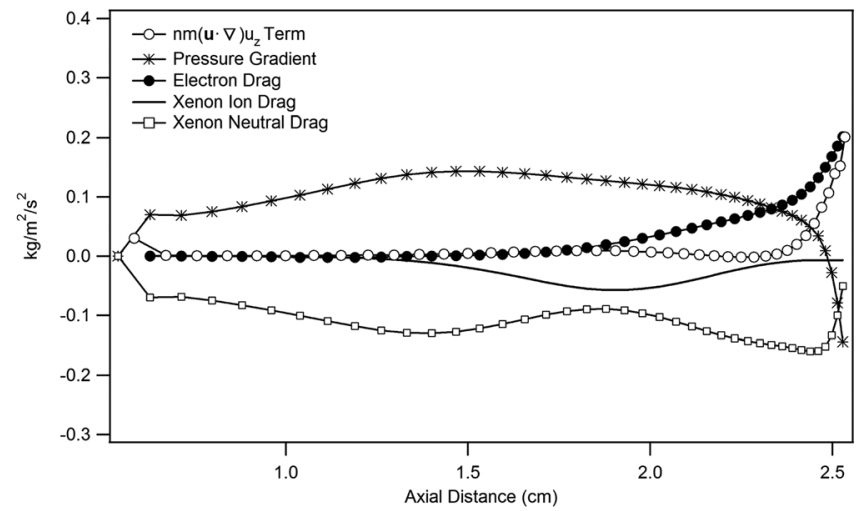

(a) $\mathrm{O}_{2}$ momentum terms: nonabsorbing case.

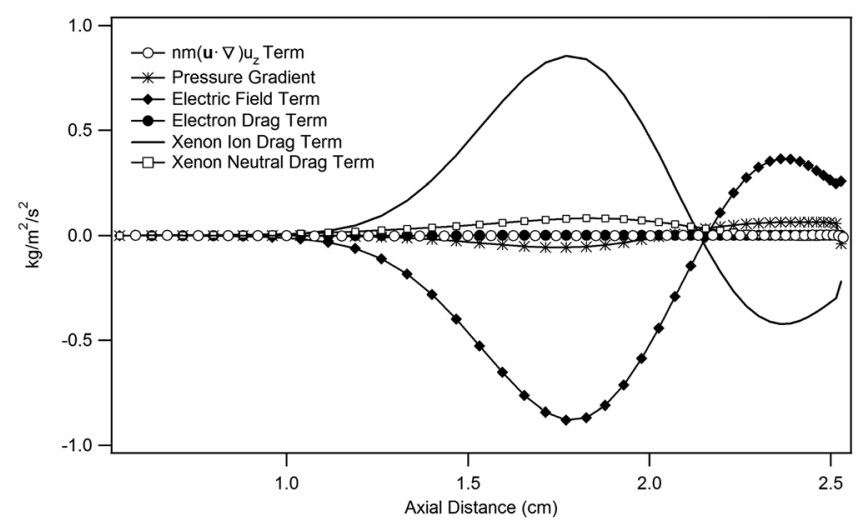

(c) $\mathrm{O}_{2}^{+}$momentum terms: nonabsorbing case.

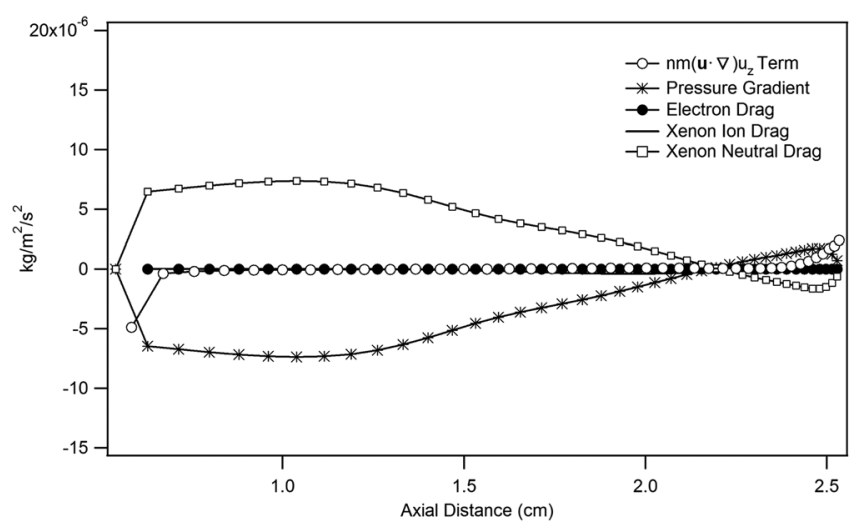

(e) O momentum terms: nonabsorbing case.

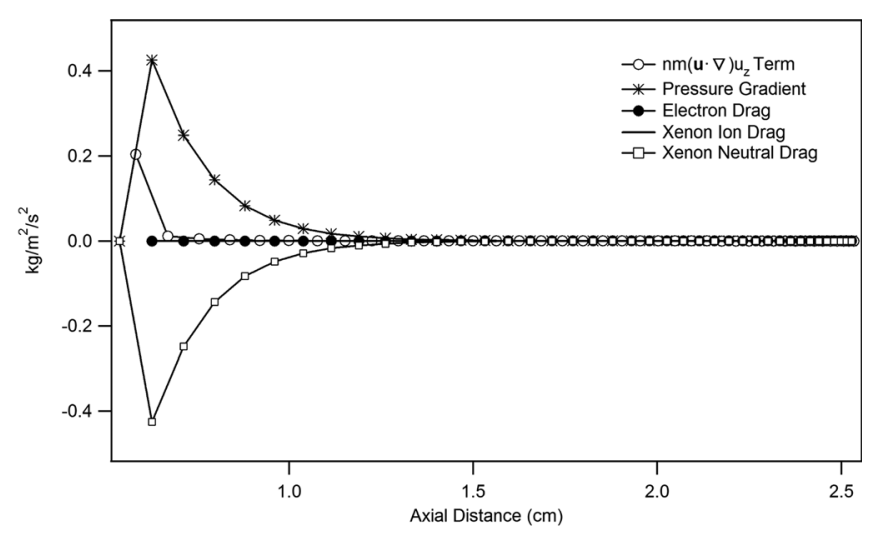

(b) $\mathrm{O}_{2}$ momentum terms: perfectly absorbing case.

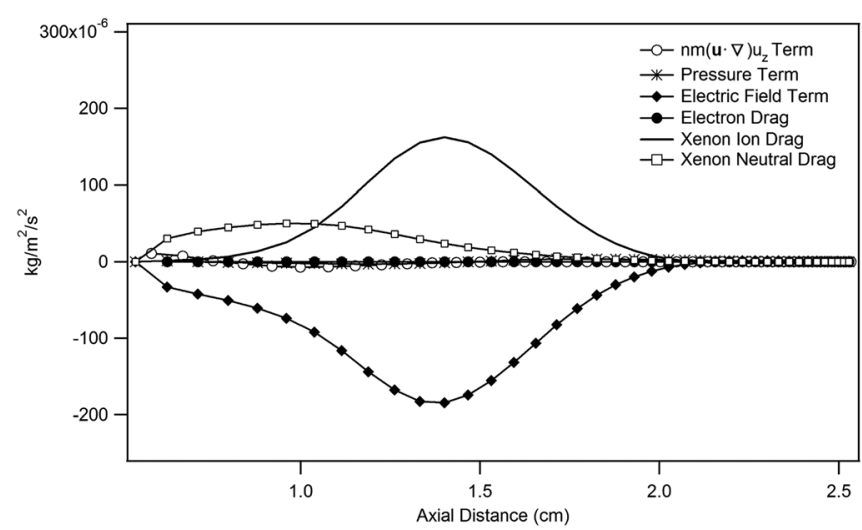

(d) $\mathrm{O}_{2}^{+}$momentum terms: perfectly absorbing case.

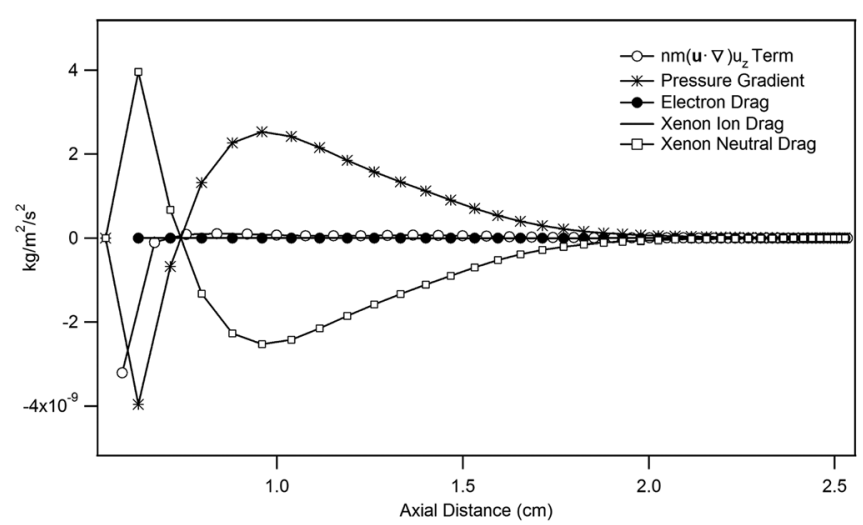

(f) O momentum terms: perfectly absorbing case.

FIG. 8. Comparison of the terms in the momentum equation given in Eq. (5) along the axis of symmetry for both boundary conditions.

\section{B. Perfectly absorbing case}

In the perfectly absorbing case, oxygen is constantly absorbed by the upstream portion of the emitter, which prevents oxygen from completely filling the discharge chamber as seen in the nonabsorbing case. The radial gradient in the density creates a diffusion flux that transports the oxygen toward the emitter surface where it is absorbed. A steep axial density gradient is formed, resulting in $\mathrm{O}_{2}$ densities that vary by four orders of magnitude along the emitter length as shown in Fig. 9(a). The $\mathrm{O}_{2}$ neutral flux to the surface is very high at the upstream end and rapidly drops off with distance.
The barium species are more dominant than the oxygen species in this case.

$\mathrm{O}_{2}^{+}$density contours and streamlines are shown in Fig. 9(b). Recall from Fig. 7 that the $\mathrm{O}_{2}$ ionization mean free path is lowest in the region between $z=1.9$ and $2.2 \mathrm{~cm}$. However, since $\mathrm{O}_{2}$ neutral densities are so low there not much ionization takes place. This moves the high ion density region further upstream, and most of the ions are generated in the region between $z=1.3$ and $1.6 \mathrm{~cm}$.

Figure 9(c) shows the density contours for atomic oxygen. Since dissociation of $\mathrm{O}_{2}$ was neglected in this model, 


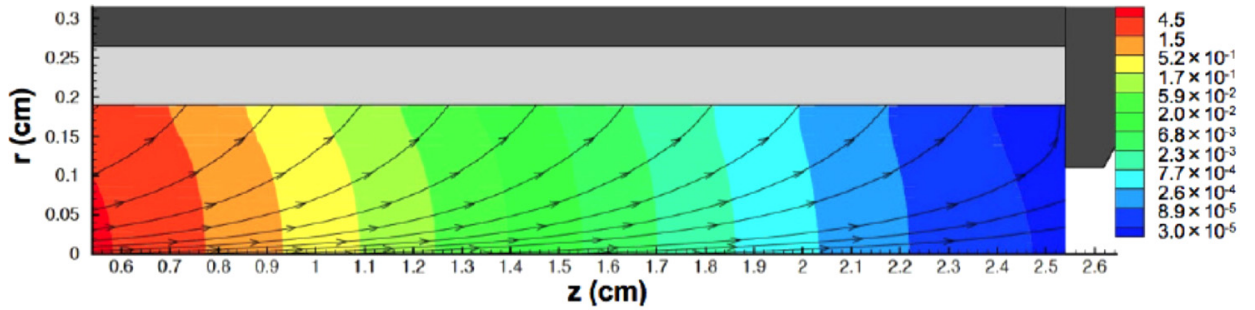

(a) $\mathrm{O}_{2}$ neutral density, $n_{\mathrm{O}_{2}}\left(10^{16} \mathrm{~m}^{-3}\right)$, and $\mathrm{O}_{2}$ streamlines.

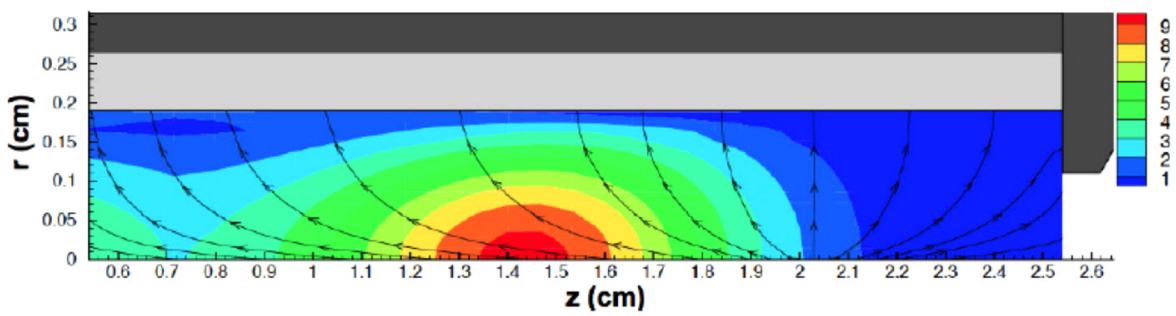

(b) $\mathrm{O}_{2}^{+}$ion density, $n_{\mathrm{O}_{2}^{+}}\left(10^{11} \mathrm{~m}^{-3}\right)$, and $\mathrm{O}_{2}^{+}$streamlines.

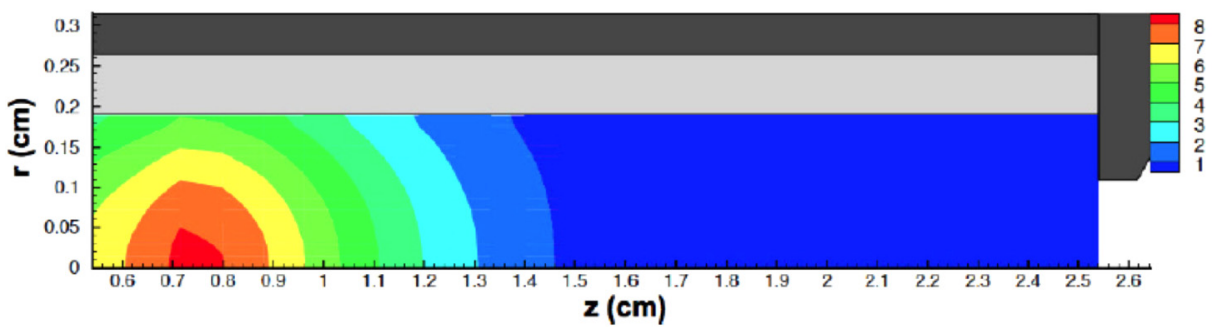

(c)O neutral density, $n_{O}\left(10^{8} \mathrm{~m}^{-3}\right)$.
FIG. 9. Oxygen solution for absorbing boundary conditions. $J_{D}=15 \mathrm{~A}$ and $\dot{m}_{X e}=3.7 \mathrm{sccm}$. the only way to generate $\mathrm{O}$ is via reactions between $\mathrm{Ba}$ and $\mathrm{O}_{2}$. Consequently, the highest density of $\mathrm{O}$ is near the inlet where the $\mathrm{O}_{2}$ number density is highest.

The terms in the expression for momentum conservation are plotted in Fig. 8 along the axis of symmetry, i.e., for $r=0$. In the solution for neutral $\mathrm{O}_{2}$ and $\mathrm{O}$ shown in Figs. 8(b) and 8(f), the Xe neutral drag and the pressure gradient are the two dominant terms throughout much of the discharge. These terms are most dominant at the upstream end as this is where the oxygen densities are highest. In the solution for $\mathrm{O}_{2}^{+}$shown in Fig. 8(d), the two dominant terms are the electric field term and the $\mathrm{Xe}^{+}$ion drag. Xe neutral drag is important upstream because of charge exchange collisions. The convective acceleration term is small everywhere for all three solutions.

\section{CONCLUSIONS}

The results presented here show the transport of barium and oxygen species in the Xe plasma as described by the conservation equations. $\mathrm{Ba}$ and $\mathrm{BaO}$ move through the emitter pores and enter into the plasma where they are ionized and transported back to the surface via the electric field. Ba is readily ionized in the emission zone as a result of its low ionization potential, and very few Ba neutrals escape through the orifice. $\mathrm{BaO}$ is not as effectively recycled because its ionization rate is lower and a non-negligible amount of $\mathrm{BaO}$ is allowed to escape through the orifice.

During poisoning, oxygen was allowed to enter the plasma discharge through the upstream inlet. The dominant ionization process for $\mathrm{O}_{2}$ molecules was resonant charge exchange with $\mathrm{Xe}^{+}$. The oxygen was also allowed to interact with $\mathrm{Ba}$ to form $\mathrm{BaO}$; however, since the reactant concentrations were small, very little $\mathrm{BaO}$ was formed in the discharge. Dissociation of $\mathrm{O}_{2}$ was not considered as the bond energy of $\mathrm{O}_{2}$ is high and dissociation cross sections are low. Therefore, $\mathrm{O}$ is generated only during reactions between $\mathrm{O}_{2}$ and $\mathrm{Ba}$, and consequently, the $\mathrm{O}$ number densities are very small.

In order to understand the transport of oxygen species in the cathode, two bounding cases were explored. The first case assumed no oxygen accumulation on the emitter surface. This boundary condition gives a uniform $\mathrm{O}_{2}$ neutral density at the prescribed concentration throughout the entire domain. Very little $\mathrm{O}_{2}$ is lost to ionization, and the $\mathrm{O}_{2}^{+}$density is more than two orders of magnitude lower than the $\mathrm{O}_{2}$ density. The oxygen is not effectively recycled in the plasma and all neutrals that escape ionization exit the cathode through the orifice.

The second boundary condition assumed the emitter to be a perfectly absorbing surface. This case is representative 
of what would occur early on in oxygen poisoning. The results give a steep gradient in the $\mathrm{O}_{2}$ density with axial distance as a result of significant oxygen gettering upstream. Although the temperatures and plasma densities are highest in the emission zone, the $\mathrm{O}_{2}$ density is so low there that not much ionization takes place and the region of maximum $\mathrm{O}_{2}^{+}$ density occurs further upstream. The results show that the pressure gradient is balanced by the Xe drag in the neutral species momentum equation, and the electric field term is balanced by the $\mathrm{Xe}^{+}$ion drag in the ion species momentum equation. The radial gradients in the $\mathrm{O}_{2}$ neutral density are small, which indicates that the oxygen flux to the surface is not diffusion-limited. Additionally, the calculated $\mathrm{O}_{2}$ flux to the surface is much higher than expected based on the slow poisoning rates observed experimentally. This suggests that the rate-limiting step for oxygen poisoning in plasma cathodes is associated with surface processes rather than transport phenomena in the gas phase.

Understanding the surface state is important since the work function will vary with barium and oxygen coverage to alter the electron emission. Future studies should aspire to solve the xenon plasma and oxygen transport models concurrently and include boundary conditions that change in time as the oxygen accumulates. This construct would allow for changes to the plasma gas and the emitter surface to constantly inform each other.

\section{ACKNOWLEDGMENTS}

The research described in this paper was carried out by the Jet Propulsion Laboratory, California Institute of Technology, under a contract with the National Aeronautics and Space Administration.

${ }^{1}$ P. Palluel and A. M. Schroff, J. Appl. Phys. 51, 2894 (1980).

${ }^{2}$ G. Haas, R. Thomas, C. Marrian, and A. Shih, IEEE Trans. Electron Devices 38, 2244 (1991).

${ }^{3}$ J. Cronin, Microwave J. 22, 57 (1979).

${ }^{4}$ J. Polk, "Long and Short Term Effects of Oxygen Contaminants on Hollow Cathode Operation," AIAA Paper 2007-5191, 2007.

${ }^{5}$ J. Cronin, Proc. IEEE 128, 19 (1981).

${ }^{6}$ R. Levi, J. Appl. Phys. 24, 233 (1953).

${ }^{7}$ R. Levi, J. Appl. Phys. 26, 639 (1955).

${ }^{8}$ R. Lipeles and H. Kan, Appl. Surf. Sci. 16, 189 (1983).

${ }^{9}$ E. Rittner, J. Appl. Phys. 48, 4344 (1977).

${ }^{10}$ E. Rittner, R. Ahlert, and W. Rutledge, J. Appl. Phys. 28, 156 (1957).

${ }^{11}$ W. Rutledge and E. Rittner, J. Appl. Phys. 28, 167 (1957).

${ }^{12}$ E. Rittner, W. Rutledge, and R. Ahlert, J. Appl. Phys. 28, 1468 (1957).
${ }^{13}$ J. Polk, I. Mikellides, and I. Katz, in JANNAF MSS/LPS/SPS Meeting, Orlando, FL, 2008.

${ }^{14}$ J. Polk, I. Mikellides, A. Capece, and I. Katz, "Barium Depletion in Hollow Cathode Emitters," AIAA Paper 2009-5197, 2009.

${ }^{15}$ J. Polk, I. Mikellides, I. Katz, and A. Capece, J. Appl. Phys. 105, 113301 (2009).

${ }^{16}$ I. G. Mikellides, Phys. Plasmas 16, 013501 (2009).

${ }^{17}$ I. G. Mikellides and I. Katz, J. Propul. Power 24, 855 (2008).

${ }^{18}$ I. G. Mikellides, I. Katz, D. M. Goebel, K. K. Jameson, and J. E. Polk, J. Propul. Power 24, 866 (2008).

${ }^{19}$ E. McDaniel, Collision Phenomena in Ionized Gases (John Wiley \& Sons, 1964).

${ }^{20}$ H. Shimamori and Y. Hatano, Chem. Phys. 21, 187 (1977).

${ }^{21}$ K. Itikawa and A. Ichimura, J. Phys. Chem. Ref. Data 19, 637 (1990).

${ }^{22}$ K. Itikawa, J. Phys. Chem. Ref. Data 38, 1 (2009).

${ }^{23}$ D. V. Fursa and I. Bray, Phys. Rev. A 59, 282 (1999).

${ }^{24}$ W. Thompson, M. Shah, and H. Gilbody, J. Phys. B: At., Mol. Opt. Phys. 28, 1321 (1995).

${ }^{25}$ D. Rapp and P. Englander-Golden, J. Chem. Phys. 43, 1464 (1965).

${ }^{26}$ J. Dettmann and F. Karstensen, J. Phys. B: At. Mol. Phys. 15, 287 (1982).

${ }^{27}$ J. Hastie, D. Bonnell, and P. Schenck, Pure Appl. Chem. 72, 2111 (2000).

${ }^{28}$ J. Hastie, "A predictive ionization cross-section model for inorganic molecules," NISTIR 6768, 2001.

${ }^{29}$ J. Huba, NRL Plasma Formulary (Beam Physics Branch, Plasma Physics Division, Naval Research Laboratory, Washington, DC, 2007).

${ }^{30}$ W. G. Vincenti and C. H. Kruger, Introduction to Physical Gas Dynamics (John Wiley \& Sons, 1965).

${ }^{31}$ B. Poling, J. Prausnitz, and J. O'Connell, The Properties of Gases and Liquids, 5th ed. (McGraw-Hill, 2001).

${ }^{32} \mathrm{~K}$. Annamalai and I. K. Puri, Advanced Thermodynamics Engineering (CRC Press, 2002).

${ }^{33}$ T. G. Walker, K. D. Bonin, and W. Happer, J. Chem. Phys. 87, 660 (1987).

${ }^{34}$ M. Lieberman and A. Lichtenberg, Principles of Plasma Discharges and Materials Processing (John Wiley \& Sons, 1994).

${ }^{35}$ T. Su and M. T. Bowers, Int. J. Mass Spectrom. Ion Phys. 12, 347 (1973).

${ }^{36}$ Comprehensive Chemical Kinetics: Selected Elementary Reactions, edited by C. Bamford and C. Tipper (Elsevier Science Publishing Co., 1976).

${ }^{37}$ S. Kwon, J. Hwang, H. Lee, and W. R. Lee, Bull. Korean Chem. Soc. 31, 2219 (2010).

${ }^{38}$ D. Lide, CRC Handbook of Chemistry and Physics, 85th ed. (CRC Press, 2004)

${ }^{39}$ R. F. Stebbings, B. R. Turner, and A. C. H. Smith, J. Chem. Phys. 38, 2277 (1963).

${ }^{40}$ D. Rapp and W. E. Francis, J. Chem. Phys. 37, 2631 (1962).

${ }^{41}$ J. S. Miller, S. H. Pullins, D. J. Levandier, Y. Hui Chiu, and R. A. Dressler, J. Appl. Phys. 91, 984 (2002).

${ }^{42}$ O. Kashireninov, V. Kuznetsov, and G. Manelis, AIAA J. 15, 1035 (1977).

${ }^{43}$ E. Murad, J. Chem. Phys. 77, 2057 (1982).

${ }^{44}$ W. Tsang and R. Hampson, J. Phys. Chem. Ref. Data 15, 1087 (1986).

${ }^{45}$ K. Schofield, Chem. Rev. 67, 707 (1967).

${ }^{46}$ J. Roquais, F. Poret, R. le Doze, J. Ricaud, A. Monterrin, and A. Steinbrunn, Appl. Surf. Sci. 215, 5 (2003).

${ }^{47}$ A. Shih, J. Yater, and C. Hor, Appl. Surf. Sci. 242, 35 (2005).

${ }^{48}$ R. Forman, J. Appl. Phys. 47, 5272 (1976). 